\title{
Cuckoos versus hosts in insects and birds: adaptations, counter-adaptations and outcomes
}

\author{
Rebecca M. Kilner ${ }^{1 *}$ and Naomi E. Langmore ${ }^{2}$ \\ ${ }^{1}$ Department of Zoology, University of Cambridge, CB2 3EJ, United Kingdom \\ ${ }^{2}$ Research School of Biology, Australian National University, Canberra 0200, Australia
}

\begin{abstract}
Avian parents and social insect colonies are victimized by interspecific brood parasites - cheats that procure costly care for their dependent offspring by leaving them in another species' nursery. Birds and insects defend themselves from attack by brood parasites; their defences in turn select counter-strategies in the parasite, thus setting in motion antagonistic co-evolution between the two parties. Despite their considerable taxonomic disparity, here we show striking parallels in the way that co-evolution between brood parasites and their hosts proceeds in insects and birds. First, we identify five types of co-evolutionary arms race from the empirical literature, which are common to both systems. These are: (a) directional co-evolution of weaponry and armoury; (b) furtiveness in the parasite countered by strategies in the host to expose the parasite; (c) specialist parasites mimicking hosts who escape by diversifying their genetic signatures; (d) generalist parasites mimicking hosts who escape by favouring signatures that force specialization in the parasite; and (e) parasites using crypsis to evade recognition by hosts who then simplify their signatures to make the parasite more detectable. Arms races a and c are well characterized in the theoretical literature on co-evolution, but the other types have received little or no formal theoretical attention. Empirical work suggests that hosts are doomed to lose arms races $\mathrm{b}$ and e to the parasite, in the sense that parasites typically evade host defences and successfully parasitize the nest. Nevertheless hosts may win when the co-evolutionary trajectory follows arms race a, c or d. Next, we show that there are four common outcomes of the co-evolutionary arms race for hosts. These are: (1) successful resistance; (2) the evolution of defence portfolios (or multiple lines of resistance); (3) acceptance of the parasite; and (4) tolerance of the parasite. The particular outcome is not determined by the type of preceding arms race but depends more on whether hosts or parasites control the co-evolutionary trajectory: tolerance is an outcome that parasites inflict on hosts, whereas the other three outcomes are more dependent on properties intrinsic to the host species. Finally, our review highlights considerable interspecific variation in the complexity and depth of host defence portfolios. Whether this variation is adaptive or merely reflects evolutionary lag is unclear. We propose an adaptive explanation, which centres on the relative strength of two opposing processes: strategy-facilitation, in which one line of host defence promotes the evolution of another form of resistance, and strategy-blocking, in which one line of defence may relax selection on another so completely that it causes it to decay. We suggest that when strategy-facilitation outweighs strategy-blocking, hosts will possess complex defence portfolios and we identify selective conditions in which this is likely to be the case.
\end{abstract}

Key words: social parasite, co-evolution, arms race, cowbird, slave-making ant, Polistes, virulence, chemical insignificance, hydrocarbon, recognition system.

\section{CONTENTS}

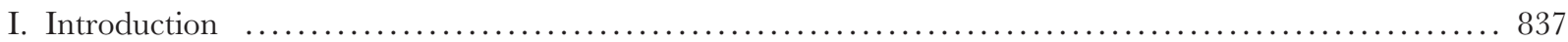

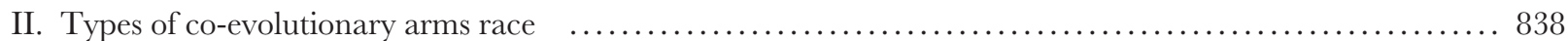

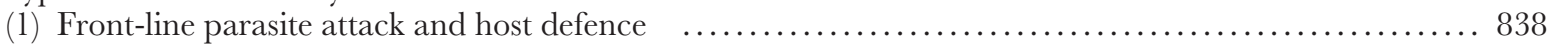

* Address for correspondence E-mail: rmk1002@cam.ac.uk 


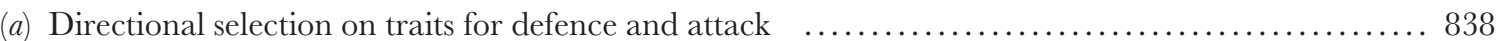

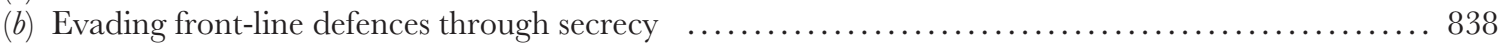

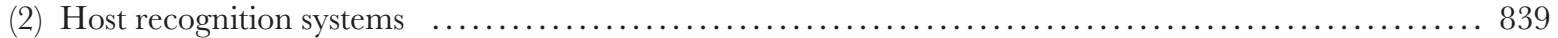

(a) Forgery of the host signature before parasitism: specialist parasites $\ldots \ldots \ldots \ldots \ldots \ldots \ldots \ldots \ldots$

(b) Forgery of the host signature after parasitism: generalist parasites $\ldots \ldots \ldots \ldots \ldots \ldots \ldots \ldots \ldots$

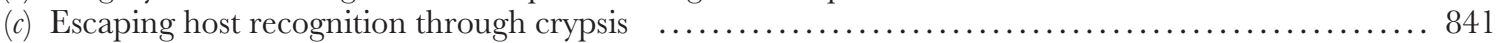

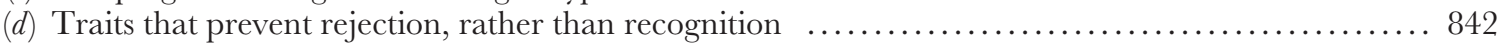

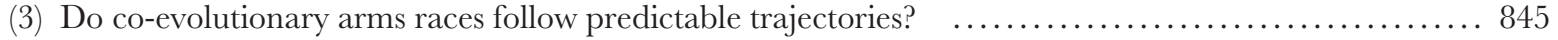

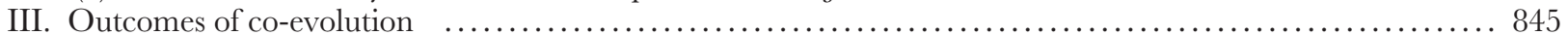

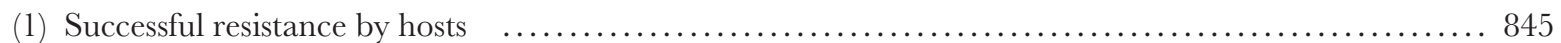

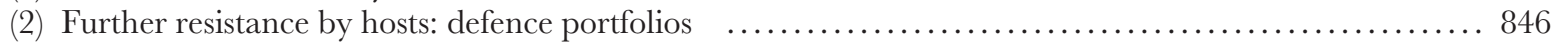

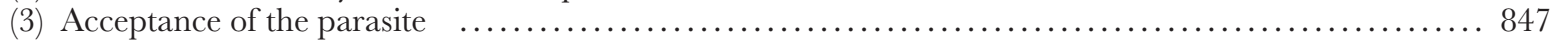

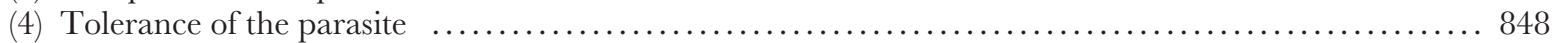

(5) Do co-evolutionary arms races yield predictable outcomes? $\ldots \ldots \ldots \ldots \ldots \ldots \ldots \ldots \ldots \ldots \ldots \ldots \ldots$

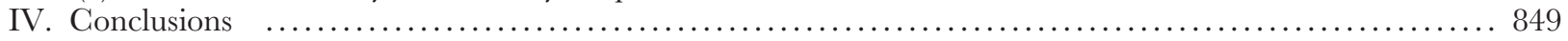

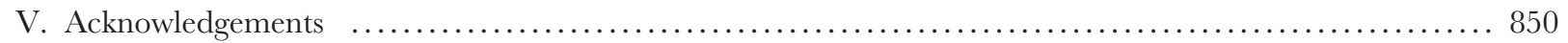

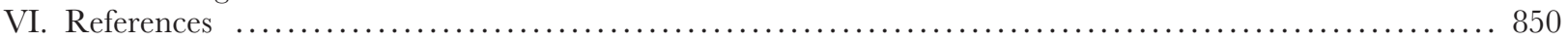

\section{INTRODUCTION}

Cooperation of any sort is usually costly and is therefore vulnerable to cheating. This is especially evident among the cooperative behaviours that centre on the rearing of dependent kin, because they are performed by adults at some personal cost (Bourke \& Franks, 1995; Clutton-Brock, 1991) but are exploited by brood parasites seeking to have their offspring raised for free. The incentive to cheat is so strong that brood parasitism has arisen both within and between species on many independent occasions. The interspecific brood parasites in particular are taxonomically diverse as well as numerous and span the birds, frogs, fish and insects (Brown, Morales \& Summers, 2009; Davies, 2000; Davies, Bourke \& Brooke, 1989; Sato, 1986).

Obligate interspecific brood parasitism is particularly well known among the birds, where it has evolved independently in seven different clades (Sorenson \& Payne, 2005), yielding roughly 100 parasitic species that are scattered across the world (Davies, 2000). These brood parasites typically lay an egg in a nest belonging to another species and then abandon it, first to be incubated by the hosts, and then reared to independence after hatching. From the host's perspective, brood parasitism is costly because at the very least it reduces their current fecundity to some extent (but see Lyon \& Eadie, 2004). The costs of parasitism select hosts that can defend themselves against attack by the parasite, and host defences reciprocally select counterstrategies in the brood parasite. The antagonistic interactions of avian obligate brood parasites and their hosts have therefore become a model system for the study of co-evolution (Rothstein \& Robinson, 1998).

Interspecific brood parasitism is also well documented among the insects (where it is often referred to as 'social parasitism'). Here the parasites target their attack especially on the social insects, such as wasps, bees, bumblebees and ants, and they appropriate a colony's workforce to rear their own young (Brandt et al., 2005a; Buschinger, 2009; Cervo, 2006; Davies et al., 1989; Dronnet et al., 2005; Pierce et al., 2002). Among the slavemaker ants, and some species of parasitic wasp (Cervo, 2006) this involves taking over a host colony and then launching multiple secondary raids on neighbouring colonies to steal host pupae, who are enslaved to rear yet more parasitic young (Brandt et al., 2005a). Although the natural history differs markedly, there are strong conceptual similarities between brood parasitism in birds and insects. In each case, at the very least, the victims of the brood parasite are forced to divert costly care away from kin towards rearing unrelated parasitic young. In some cases, such as with hosts of cuckoos or slave-making ants, the brood parasite reduces host fecundity directly by removing host young from the nest. There is now evidence from diverse social insect systems that victims defend themselves against parasitism, and that their defences have selected counter-adaptations in the parasite (e.g. Bogusch, Kratochvil \& Straka, 2006; Brandt et al., 2005a; Cervo, 2006; Martin, Helanterä \& Drijfhout, 2010b). Just as in birds, insect brood parasites and their hosts co-evolve.

Despite their taxonomic disparity, co-evolution with brood parasites exposes social insects and avian parents to convergent selective pressures. It is therefore interesting to examine just how much these two systems have in common with each other. The aim of this review is to address two broad questions, which have not been considered in previous comparisons of avian and insect brood parasites. The first question asks how the co-evolutionary arms race proceeds. Do certain sorts of host defences predictably select certain sorts of counter-adaptations in the parasite, for example, and therefore do we see the same types of host defences and parasite counter-adaptations in both the birds and the insects? The second question addresses the outcome of coevolution. Are there predictable endpoints, common to both insects and birds, and are some arms races more likely to favour victory for the parasite rather than the host (or vice versa)? Although we draw on diverse studies from both insects and birds to answer these questions, here we have not attempted an exhaustive survey of the vast literature on co-evolution in each taxonomic system. Our focus instead 
is on common concepts. We apologise at the outset to the many researchers whose work we were unable to include in this review simply for reasons of brevity.

\section{TYPES OF GO-EVOLUTIONARY ARMS RACE}

\section{(1) Front-line parasite attack and host defence}

Bird and social insect nurseries (see Mock \& Parker, 1997 for a definition of 'nursery') are extremely well defended by their owners, so the parasite's first task in appropriating this resource commonly involves breaching the various physical lines of defence that protect the nest.

\section{(a) Directional selection on traits for defence and attack}

In some cases, the co-evolutionary arms race of defence, counter-attack and counter-defence is reminiscent of coevolution in a classical predator-prey arms race. Initially, there is directional selection for the host to defend itself against attack from the parasite. Host defences then select for improved armoury in the parasite which, in turn, places hosts under directional selection to overcome this improvement in the parasite (Barrett, Rogers \& Schluter, 2008; Nuismer, Ridenhour \& Oswald, 2007). There is evidence from the insects for each of these three stages in the arms race. For example, only some hosts of Sphecodes cuckoo bees exhibit defences and fighting behaviour when the parasitic bee attempts to enter the nest, suggesting that these traits do not pre-date an association with brood parasites and that some hosts have only reached the first stage of the arms race (Bogusch et al., 2006). Evidence for the second stage comes from Bombus (Psithyrus) cuckoo bumblebees, which now possess thicker cuticles and longer stings than their hosts to enable the parasite to breach host defences effectively (Fisher \& Sampson, 1992). Likewise, some species of Polistes cuckoo wasps battle their way into the host colony and they possess specially enlarged and strengthened head, mandible and leg segments for this purpose (Cervo, 2006). Finally, Polistes dominulus hosts of the cuckoo wasp Polistes sulcifer, have reached the third stage of this arms race. In response to parasitism, these hosts have apparently increased their body size because wasps from parasitized populations are larger in almost every respect than those from unparasitized populations (Ortolani \& Cervo, 2010).

\section{(b) Evading front-line defences through secrecy}

In some cases, parasites switch from attempting to out-gun host front-line defences to evading hosts simply by avoiding further confrontation. For example, a queen of the slavemaking ant Polyergus rufescens withstands initial vicious attack from host Formica sanguinea workers, as she penetrates a host colony, with an integument that is apparently especially thickened for this purpose (Mori et al., 2000). The parasitic queen then launches a brief and violent counter-attack from which she emerges unscathed but which causes host workers to lose antennae or legs (Mori, D'Ettorre \& Le Moli, 1995). The parasite's success in counter-attacking is largely due to a secretion from her Dufour's gland, which acts as an appeasement allomone and greatly reduces the incidence of worker aggression. This further enables the parasitic queen to move freely to attack the host queen (Mori et al., 2000) whom she quickly kills with bites to the head, thorax and gaster (Mori et al., 1995). Similar deployment of appeasement allomones is observed in the congeneric slavemaker P. sumarai when attacking host $F$. japonica colonies (Tsuneoka \& Akino, 2009).

Avoidance of confrontation is taken to a greater level in Sphecodes cuckoo bees and in the common cuckoo Cuculus canorus. When parasitizing some hosts, for example, cuckoo bees will only enter the host nest when the host female is absent, and will sometimes even wait nearby until the host has departed (Bogusch et al., 2006). Likewise, to avoid mobbing by their hosts (Welbergen \& Davies, 2009), common cuckoos are exceptionally furtive around the host nest (Davies \& Brooke, 1988). Like the cuckoo bees, common cuckoo females choose to visit the nest when the host is absent, and they also lay their egg in the early afternoon rather than the morning to avoid encountering the nest owner as she herself lays an egg. In addition, the time spent by the cuckoo at the host nest is very brief, because the act of egg-laying is so rapid, and this too minimizes the likelihood of a confrontation between the parasite and its host (Davies \& Brooke, 1988). Great-spotted cuckoos Clamator glandarius are just as secretive around the nest because they risk serious injury from attack if discovered by their larger corvid hosts. In this brood parasite, males seemingly distract hosts away from the nest with conspicuous calling behaviour as their mate quietly glides to the host nest and quickly adds an egg of her own (Davies, 2000).

While cuckoos are under selection to avoid coming face to face with their hosts, there is some evidence that hosts are counter-selected to increase the chance of a confrontation with their parasite. For example, the loud host alarm calls triggered by the presence of an avian brood parasite near the nest attract the attention of nearby conspecifics and even heterospecifics who join in mobbing the parasite until it leaves the nest's vicinity (Trivers, 1971; Welbergen \& Davies, 2009). Mobbing behaviour appears to have counter-selected for mimicry in adult common cuckoos, who now resemble hawks with their barred chest plumage. Barring seemingly induces fear in potential hosts, which limits the extent of their mobbing, and thereby conceals the cuckoo's presence from at least some members of the host population (Davies \& Welbergen, 2008).

The entrance tubes that some Ploceus hosts of the diederik cuckoo Chrysococcyx caprius weave on the front of their nests may also function to render the parasite more apparent to hosts. The tubes' diameter is sufficiently narrow to prevent the cuckoo from gaining rapid access to the nest and there are anecdotal reports of hosts attacking diederik cuckoos that become trapped as they attempt to sneak into the host nest (Davies, 2000). Nevertheless, the entrance tubes offer only a limited deterrent to parasites and Ploceus species whose nests possess such structures are still frequent 
victims of the diederik cuckoo (Davies, 2000). Host front-line defences can be effective means of deterring brood parasites (e.g. Welbergen \& Davies, 2009), sometimes even forever (e.g. Mori et al., 1995; Ortolani \& Cervo, 2010). Nevertheless, empirical evidence to date suggests that defences on the front lines are doomed to fail if the parasite responds by using subterfuge rather than direct confrontation.

\section{(2) Host recognition systems}

Having bludgeoned its way past host front-line defences, or circumvented them by more subtle means, the parasite sets about commandeering host resources for its own reproduction. At this point it encounters the elaborate recognition systems used by hosts to protect the nursery's resources from marauders and these become the focus of further co-evolution between the parasite and the host. Theoretical genetic analyses show that parasites are placed under selection to mimic their hosts, effectively forging their host's signature, which in turn selects hosts that escape this mimicry through diversification and elaboration of their signature (Gavrilets, 1997; Kopp \& Gavrilets, 2006; Nuismer, Doebeli \& Browning, 2005; Takasu, 2003). Parasites thus chase their hosts through signature space, sometimes in circles and sometimes in branching linear trajectories, depending on the particular assumptions of the theoretical model, and polymorphisms in host signatures and parasite forgeries are a common predicted outcome. As we shall see, case studies from both the avian and insect social parasites support these general predictions from theory and also reveal co-evolutionary trajectories not yet imagined by theoretical work. Importantly, the precise way in which the parasite eludes the recognition system critically affects the co-evolutionary arms race that ensues.

\section{(a) Forgery of the host signature before parasitism: specialist parasites}

This section considers evasion of recognition through forged signatures in the parasite that are present before parasitism, and that are probably inherited genetically. Among the birds, eggshell colour and patterning are common signatures of offspring identity. Although environmental conditions can induce small variations in the precise colour and pattern adorning an egg, most of the variation in egg appearance is controlled genetically and individual females lay eggs of a consistent phenotype throughout their lives, whether they are hosts or parasites (reviewed by Kilner, 2006). Avian egg signatures have been especially well characterized in the many hosts of the common cuckoo. In general, hosts discriminate against eggs that look odd by comparison with their own and the greater the discrepancy in appearance, the more likely they are to reject the egg (Brooke \& Davies, 1988; Lahti, 2006; Moksnes, Røskaft \& Braa, 1995). Egg discrimination is a co-evolved response to parasitism because species that have no evolutionary history of interaction with the cuckoo lack this ability (Davies \& Brooke, 1989). The signatures themselves, the diversities of egg colouring and the intricacies of egg patterning, are also an evolved response to parasitism because former cuckoo hosts that are no longer exposed to parasitism are less variably coloured and less elaborately maculated (Lahti, 2005). Egg recognition and rejection has in turn driven the evolution of cuckoo egg mimicry: the more discriminating the host, the closer the match between cuckoo and host eggs (Aviles et al., 2010; Cassey et al., 2008; Spottiswoode \& Stevens, 2010; Stoddard \& Stevens, 2010). The most recent work in this area takes account of the fact that bird visual systems differ markedly from our own, most notably by extending into the ultraviolet, and uses techniques of avian visual modelling to quantify the extent of mimicry in colour and pattern through the eyes of a bird, the intended perceiver of the eggshell signature. It has revealed finely tuned levels of mimicry in colour and pattern that are essentially cryptic to the human eye (Aviles, 2008; Aviles et al., 2010; Cassey et al., 2008; Spottiswoode \& Stevens, 2010; Stoddard \& Stevens, 2010). So there is compelling evidence that discrimination and rejection by hosts has driven the evolution of exquisite cuckoo egg mimicry, at least in some instances (but see Moksnes et al., 1995). One consequence has been that the common cuckoo has split into genetically distinct host-specific lines, each specializing on one host by laying an egg that resembles their host's clutch (Fossøy et al., 2011; Gibbs et al., 2000). Mimetic cuckoo eggs have, in turn, caused hosts to diversify their egg signatures. In general, there is more variation in egg appearance among clutches of parasitized populations than is seen in eggs laid by populations that have never been exposed to brood parasitism (reviewed by Kilner, 2006). In one host of the common cuckoo, the ashy-throated parrotbill Paradoxornis alphonsianus from China, clutches have diversified so much that hosts now possess an egg polymorphism (Yang et al., 2010).

How have cuckoos responded to this increase in host egg diversity? Genetic analyses show that there are several mtDNA haplotypes within each host race, suggesting that cuckoos routinely switch between hosts, perhaps when temporarily defeated by increased diversification in egg signatures produced by their former hosts, and the corresponding increase in host discrimination that results (Davies \& Brooke, 1989; Gibbs et al., 2000; Marchetti, 2000). If cuckoos can keep up with their hosts as they chase through signature space, and cuckoo egg mimicry becomes more and more refined, hosts are more likely to make discrimination errors and mistakenly reject their own eggs instead of the cuckoo's, sometimes removing eggs from clutches that are not even parasitized (Marchetti, 1992). At some point, when rejection costs start to outweigh the benefits of discrimination, hosts can gain greater fitness on average by accepting all eggs, even the occasional cuckoo, especially at very low levels of parasitism (Brooke, Davies \& Noble, 1998; Davies, Brooke \& Kacelnik, 1996; Langmore \& Kilner, 2009; Marchetti, 1992). Consequently, hosts start to benefit by using phenotypically plastic discrimination rules, only showing egg rejection at high levels of parasitism when the benefits outweigh any associated costs (e.g. Brooke et al., 1998; Hauber, Moskat \& Ban, 2006; Langmore et al., 2009a; Rodriguez-Girones \& Lotem, 1999). As we shall see in Section III.3, recognition 
costs associated with egg rejection are crucial in determining the outcome of co-evolution.

Recent work suggests that the equivalent recognitionbased co-evolutionary interactions of social insects and their parasites are likely to follow remarkably similar trajectories to those identified in cuckoos and their hosts. Here, recognition centres on hydrocarbon signatures in the insect (or egg) cuticle, in particular the alkenes, di- and trimethylalkanes (Martin, Helanterä \& Drijfhout, 2008a), which can occur in a number of positional isomers and so can readily encrypt information about colony or species identity (Lenoir et al., 2001; Martin etal., 2010a,b; Martin \& Drijfhout, 2009). Social insect parasites are versatile mimics of these hydrocarbon signatures (e.g. Lenoir et al., 2001; Martin et al., 2010a), and in some cases mimicry is due to the biosynthesis of host-specific signatures prior to parasitism (e.g. Martin et al., 2010a,b). Among bumblebees (Bombus spp.), for example, hosts discriminate against individuals lacking the correct hydrocarbon signature, and the greater the mismatch, the more violent their reaction (Dronnet et al., 2005). To escape host recognition, different species of Bombus (Psithyrus) cuckoo bumblebees accurately reproduce the different alkene isomer profiles of their particular Bombus hosts, and these are apparently present in the cuckoo bumblebee cuticle before it enters the host colony (Martin et al., 2010a). So just as with the avian cuckoos, hosts discriminate against individuals that are unlike their own kind and this has selected parasites that can genetically forge the host hydrocarbon signature and so evade recognition. And, just like common cuckoo hosts, insect cuckoo hosts appear to respond to mimicry by diversifying their signatures. Populations of host Formica fusca ants that are exposed to parasites possess more diverse hydrocarbon signatures, and in particular more dimethylalkane isomers, than those that are free from parasite pressure (Martin et al., 2010b). In some cases, there is suggestive evidence that parasites may have responded by switching hosts. For example, Martin et al. (2010a) argue that British populations of the cuckoo bumblebee Bombus (Ps.) sylvestris may recently have switched to parasitizing B. pratorum. Nevertheless, parasites can track even fine changes in the hydrocarbon signature and become specialized on particular hosts (e.g. Bogusch et al., 2006). In the extreme case of the hoverfly Microdon mutabilis parasite of Formica lemani ant colonies, females (but not males) are host specific at the colony level meaning that successful parasitism involves reinfecting the same ant nest for generation after generation (Schönrogge et al., 2006). Although the precise mechanisms underpinning recognition are still unknown, host specificity that is confined to the female line is reminiscent of some common cuckoo populations (Gibbs et al., 2000), suggesting that the key recognition cues in this system might also reside in the parasitic egg (Schönrogge et al., 2006 but see Fossøy et al., 2011).

\section{(b) Forgery of the host signature after parasitism: generalist parasites}

It is common for insect brood parasites to adopt a strategy of chemical camouflage and acquire the colony-specific hydrocarbon signature after parasitism. Parasites may biosynthesize the appropriate hydrocarbon signature themselves, through altered gene expression, or it may be acquired by mechanical transfer soon after entering the host nest (Lenoir et al., 2001). For example, the caterpillar of the cuckoo butterfly Maculinea rebeli exploits several different Myrmica ant species, each with their own signature (Elmes et al., 2002), which the parasitic caterpillars acquire after adoption (Akino et al., 1999). Similarly, the generalist social parasite paper wasp Polistes atrimandibularis changes its hydrocarbon signature to mimic its host, but only after taking over the host colony (Bagneres et al., 1996). Just one equivalent example is known so far from the avian brood parasites (Langmore et al., 2008). The generalist Horsfield's bronze-cuckoo Chalcites basalis exploits diverse hosts whose nestlings differ in their begging calls (Langmore et al., 2008). Hosts abandon chicks with odd-sounding begging calls (Langmore, Hunt \& Kilner, 2003) and the cuckoo nestling flexibly adjusts the structure of its call after hatching to mimic the calls of the particular host's own young. Remarkably, there are no models from whom the cuckoo chick can learn because it evicts host young from the nest soon after hatching. Instead, host parents must somehow train the young parasite to make the appropriate-sounding begging call (Langmore et al., 2008), and so are inadvertently complicit in their own deception.

The principal co-evolutionary consequence of forging the host's signature after parasitism, rather than expressing it beforehand, is that parasites can be individual generalists, capable of flexibly adapting to exploit any of their hosts. Consequently there is no segregation into genetically distinct host-specific lineages within species (Als et al., 2004; Fanelli et al., 2005; Langmore et al., 2008). Otherwise, co-evolution proceeds in a broadly similar way to the cases where the forged signature is expressed before parasitism. Insect hosts place parasites under selection to refine their mimicry of the host hydrocarbon signature which, in some cases, gives rise to parasites that become more and more chemically invisible themselves, effectively presenting a blank slate to be daubed with their hosts' particular hydrocarbons (Brandt et al., 2005a; D'Ettore \& Errrard, 1998; Lenoir et al., 2001). Parasites place hosts under selection to escape mimicry, although presumably with this mode of forgery, signature diversification alone is not sufficient to prevent the parasite from acquiring the signature upon entering the host nest. Instead, hosts may diversify their signatures in a very particular way, by specifically incorporating particular hydrocarbons that parasites find hard to absorb onto their cuticles. There is evidence of this from Leptothorax hosts of the slave-making ant Harpagoxenus sublaevis (Bauer et al., 2010). Whereas closely related ant species usually have similar hydrocarbon profiles, hosts $L$. muscorum and $L$. acervorum are unusually distinct, suggesting that they have diversified under selection from their slave-making parasite. In particular, the L. acervorum signature lacks the short-chained hydrocarbons that dominate the signature of L. muscorum, and that are more easily transferred to the parasite. Perhaps it is no 
coincidence that $L$. acervorum, whose signature is now harder for the slavemaker to forge, is also now the less favoured host (Bauer et al., 2010). In a different host-slavemaker system, two Temnothorax ant hosts of the slavemaker Protomognthus americanus appear to have become equally effective at preventing parasite forgery of their respective species' signatures, and the parasite's signature clusters between the two hosts', mimicking neither very accurately (Brandt et al., 2005b). As a consequence, host workers can much more readily defend their colony and the slavemaker suffers higher losses during raids than it does in populations where it specializes on just one host (Brandt \& Foitzik, 2004).

This suggests that if parasites are to continue to chase their hosts through signature space, they must start to specialize on one host alone (see also Rothstein, Patten \& Fleischer, 2002). Consistent with this idea, there are indications of species in transition from generalist to pure species-specialist in both the birds and the insects. For example, although $H$. sublaevis currently parasitizes two hosts, it is better adapted to L. muscorum than L. acervorum. Not only can it more easily acquire this host's signature, it also biosynthesizes two of this host's cuticular substances itself, a clear indication that it is starting to acquire the genetic adaptations for specialization (Bauer et al., 2010). Under recurrent selection from a single species, it appears that previously phenotypically plastic traits in the parasite start to become genetically accommodated (West-Eberhard, 2003). Similarly, although the slavemaker Polyergus rufuscens and the Horsfield's bronze-cuckoo are generalists, they each emerge bearing the appropriate adaptations for exploiting their primary host. Newly hatched Horsfield's bronze-cuckoo nestlings beg like nestlings of their primary malurid hosts, but can modify their calls if they find themselves being raised by a secondary host (Langmore et al., 2008). Likewise, newly emerged $P$. rufescens workers reared in isolation in the laboratory bear a hydrocarbon signature that is remarkably similar to their primary host $F$. cunicularia. Nevertheless, when introduced into nests of different hosts they are capable of acquiring the appropriate hydrocarbon signature to exhibit a high degree of mimicry of various host species (D'Ettorre et al., 2002). Whatever the means by which parasites refine their mimicry of the host's cuticular signature, there are signs that recognition becomes increasingly costly for hosts because they exhibit temporal plasticity in their rejection thresholds, only becoming discriminatory at times when they are especially vulnerable to parasite attack (Brandt et al., 2005b; D'Ettorre et al., 2004; but see Johnson, Wigenburg \& Tsutsui, 2011).

\section{(c) Escaping host recognition through crypsis}

A third way in which parasites can evade the host recognition system is effectively to become invisible. Though best characterised in terms of 'chemical insignificance' for insect parasites (Lenoir et al., 2001), it is also a ploy adopted by some avian brood parasites. For example, some members of the Chalcites cuckoo genus lay a curiously immaculate matt olive-green or brown egg, which is quite unlike the white speckled eggs laid by their Gerygone spp. or Acanthiza spp. hosts. Marchant (1972) speculated that this egg colouration had been selected for crypsis in the dark domed nests of the typical Chalcites cuckoo host. Modern techniques of avian visual modelling allow us to view the egg through the eyes of the bird and they confirm Marchant's suspicions: the egg is essentially cryptic to hosts when seen against the brown lining within the dim interior of the host nests (Langmore et al., 2009b). The evolution of crypsis as a route to evading host recognition establishes quite a different coevolutionary arms race to those seen when parasites mimic host signatures. In the case of the little bronze-cuckoo Chalcites minutillus, at least, crypsis means that the cuckoo always beats Gerygone spp. host defences at the egg stage of the breeding cycle (Langmore et al., 2009b). There is nothing hosts can do with their own eggs to make the parasitic egg more detectable.

For insect parasites, becoming cryptic means becoming 'chemically insignificant' and bearing a cuticle that is almost entirely devoid of hydrocarbons synthesized by its owner (Lenoir et al., 2001). Hosts are then caught in a sensory trap and forced to accept the parasite because discriminating against chemically insignificant individuals would also cause them to reject newly emerged, callow workers, which lack hydrocarbon signatures (Lenoir et al., 2001). Chemical insignificance is of particular importance for ant social parasites, especially the queen-tolerant and queen-intolerant inquilines as well as the Polyergus spp. and Myrmoxenus spp. slavemakers, who rely on their invisibility to slip unnoticed into host colonies and completely lack fighting adaptations with which to battle their way in or to defend themselves if they are spotted by hosts (Brandt et al., 2005a). Similarly, the egg cuticles of the parasitic hornet Vespa dybowskii are almost entirely devoid of any complex hydrocarbons, making them more or less invisible to host recognition systems (Martin et al., 2008b). The co-evolutionary arms race that ensues from chemical insignificance is, we suggest, exactly the opposite of those that result when parasites mimic host signatures. If parasites reduce the complexity of their hydrocarbon signatures to evade host detection, then hosts can render parasites detectable only if they themselves have simplified their signature to a greater extent. Parasites and hosts should then race each other through signature space to possess the least complex signature (see Fig. 1), although selection on host recognition systems from other sources (Brandt et al., 2005a) may mean that they will always bear a more complex signature than their parasite.

Is there any evidence that this is the case? A recent review of ant cuticular hydrocarbons provides some data with which to test this idea, albeit in a rather rough and ready way. Martin \& Drijfhout (2009) classify, on the basis of their complexity, the hydrocarbons produced by 78 species of ants. Cross-referencing their list with three reviews of ant social parasitism (Buschinger, 2009; Hölldober \& Wilson, 1990; Lenoir et al., 2001) reveals nine species of parasitic ant (including three species of guest ant, one queen-tolerant inquiline and five slave-making species) and seventeen host 
host

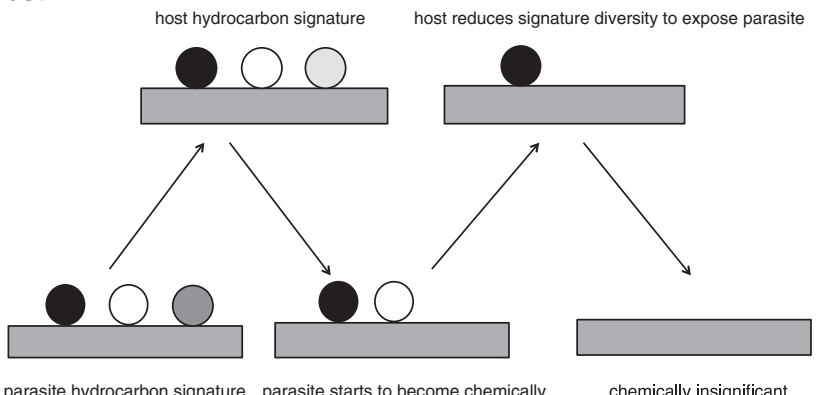

insignificant

parasite

Fig. 1. How co-evolution between insect brood parasites and their hosts might reduce cuticular hydrocarbon diversity. Hosts start by possessing a unique hydrocarbon signature for identifying members of their own species (the bar symbolizes the insect cuticle, while each shaded circle is a different sort of hydrocarbon). The parasite's hydrocarbon signature does not initially match the host's but the parasite can evade detection by simplifying its signature so that no part of it stands out when compared with the host. By simplifying its own signature in response, the host can expose the parasite. This process continues until the parasite has no signature of its own and is chemically invisible or 'insignificant'. The net result is reduced cuticular hydrocarbon diversity in both the parasite and the host.

species (Table 1). (For the remainder, we could find no record of their involvement in parasitism, whether as parasites or hosts). We used this dataset to test a specific prediction: that co-evolution has reduced diversity (i.e. reduced the variance) in the hydrocarbon signature of both hosts and parasites. We classified species as either 'co-evolved' (current hosts and parasites) or 'not exposed to co-evolution' (current non-hosts) and, using Levene's tests, compared the variance in six types of cuticular hydrocarbons (Table 1) between the two categories of species. Martin \& Drijfhout (2009) argue that the more complex hydrocarbons contribute most to the uniqueness of a hydrocarbon signature. We therefore expected to see the greatest loss in diversity in the di- and trimethylalkanes expressed by co-evolved species, when compared with the species with no (known) history of co-evolution. Since Martin \& Drijfhout (2009) found no phylogenetic signal in the complexity of the hydrocarbon signature, our analysis made no attempt to control for phylogeny.

The results are shown in Fig. 2. As predicted, we found that the di- and trimethylalkanes showed considerably less variance in co-evolved species than in those with no (known) history of co-evolution (Table 2). The diversity of other cuticular hydrocarbons was, by contrast, unaffected by coevolution (Table 2), which rules out the possibility that the lower variation in 'co-evolved' species is simply due to a smaller sample size. The results of this admittedly crude preliminary analysis are therefore consistent with the suggestion that chemical insignificance drives the evolution of simpler hydrocarbon signatures in both hosts and parasites.
However, further work, involving a more rigorous analysis, is required before our hypothesis can be accepted.

\section{(d) Traits that prevent rejection, rather than recognition}

If parasites fail to fool their host's recognition system, they could still persist in the host nest if they nevertheless manage to avoid being rejected. Among the social insects, it is hard to find examples of traits that have co-evolved to prevent rejection, rather than to confound host recognition systems or to evade front-line defences, and the co-evolutionary arms races of such traits are largely unknown. One example may come from Polistes obligate brood parasites. $P$. sulcifer parasites possess a thickened cuticle and their abdominal segments fit together unusually closely. Both traits are regarded as adaptations to prevent the penetration of host stings, which are deployed once the host has recognized the parasite (Cervo, 2006). A different technique for evading rejection comes from the cuckoo bumblebees. In a few species of these parasites, the hydrocarbon signature is a poor match of the host. Intriguingly, species that are poor mimics also produce dodecyl acetate, which is a known repellent of host workers (Martin et al., 2010a). Likewise, the xenobiotic wood ant Formicoxenus nitidulus secretes a chemical deterrent when picked up which causes host workers to drop it immediately (Martin, Jenner \& Drijfhout, 2007). Perhaps by using chemical measures to keep workers at bay, these parasitic species avoid encountering the host's recognition systems altogether and thereby evade rejection.

Among the avian brood parasites, eggshell strength is well known for the role it serves in preventing egg rejection. The largest hosts can potentially reject a parasitic egg by grasping the whole egg within their bill, but this is impossible for smaller hosts (Antonov et al., 2009; Spaw \& Rohwer, 1987) who constitute the majority of avian brood parasite victims. They must first puncture the shell in order to be able to grasp the egg firmly enough to lift it from the nest (Spaw \& Rohwer, 1987). This, in turn, has selected parasites whose eggs are strong enough to resist puncturing. An increase in eggshell thickness can confer greater puncture resistance (Picman, 1989) and parasitic cowbird Molothrus spp. (Brooker \& Brooker, 1991; Picman, 1989; Spaw \& Rohwer, 1987) and Clamator cuckoo eggshells (Brooker \& Brooker, 1991) are unusually thick for their size. Among Cuculus cuckoos, shells are exceptionally dense and this too confers increased structural strength (Picman \& Pribil, 1997). Interestingly, the Chalcites cuckoos from Australia seem not to possess eggshells that are especially strong (Brooker \& Brooker, 1991), but their hosts are poor egg rejectors (Brooker \& Brooker, 1996; Langmore et al., 2005) perhaps because Chalcites cuckoo eggs are too mimetic (Langmore \& Kilner, 2009) or too cryptic (Langmore et al., 2009b) to be detected easily and accurately. Shell strengthening thus seems to have evolved in direct response to host egg rejection behaviour, a conclusion further bolstered by intraspecific analyses of common cuckoo eggs. Recent work has found that shell thickness is greater in races of the common cuckoo whose hosts are more likely to reject odd-looking eggs (Spottiswoode, 2010). Nevertheless, 
Table 1. The number of different $n$ alkanes, alkenes, dienes, monomethylalkanes, dimethylalkanes and trimethylalkanes exhibited by 78 species of ant, with respect to their exposure to co-evolution resulting from social parasitism. Hydrocarbon data were taken from Martin \& Drijfhout (2009). 'Ant status' refers to the mode of reproduction shown by each species, and was collated from information presented in Hölldobler \& Wilson (1990); Lenoir et al. (2001) and Buschinger (2009). Species not currently described as hosts (non-hosts) were classified as 'not co-evolved'. All other species were classified as 'co-evolved'

\begin{tabular}{|c|c|c|c|c|c|c|c|c|}
\hline Species & $n$ alkanes & Alkenes & Dienes & Monomethylalkanes & Dimethylalkanes & Trimethylalkanes & Ant status & Co-evolved? \\
\hline Acromyrmex subterraneanus & 1 & 0 & 0 & 7 & 7 & 0 & non-host & not co-evolved \\
\hline Atta columbica & 1 & 0 & 0 & 0 & 0 & 2 & non-host & not co-evolved \\
\hline Formicoxenus nitidulus & 1 & 1 & 1 & 7 & 0 & 0 & xenobiotic & co-evolved \\
\hline Formicoxenus provancheri & 1 & 2 & 0 & 12 & 11 & 0 & xenobiotic & co-evolved \\
\hline Formicoxenus quebecensis & 1 & 2 & 1 & 10 & 11 & 0 & xenobiotic & co-evolved \\
\hline Harpagoxenus sublaevis & 1 & 1 & 0 & 6 & 1 & 0 & dulotic & co-evolved \\
\hline Leptothorax acervorum & 1 & 2 & 1 & 8 & 3 & 0 & host & co-evolved \\
\hline Leptothorax gredleri & 1 & 0 & 0 & 5 & 0 & 0 & non-host & not co-evolved \\
\hline Leptothorax kutteri & 1 & 1 & 1 & 2 & 0 & 0 & inquiline & co-evolved \\
\hline Leptothorax muscorum & 1 & 0 & 0 & 5 & 4 & 0 & host & co-evolved \\
\hline Leptothorax nylanderi & 1 & 0 & 1 & 14 & 22 & 0 & non-host & not co-evolved \\
\hline Myrmicaria eumenoides & 1 & 6 & 0 & 1 & 0 & 0 & non-host & not co-evolved \\
\hline Manica rubida & 1 & 0 & 0 & 6 & 2 & 0 & non-host & not co-evolved \\
\hline Myrmica alaskensis & 1 & 2 & 1 & 10 & $\overline{9}$ & 0 & host & co-evolved \\
\hline Myrmica incompleta & 1 & 2 & 1 & 12 & 10 & 0 & host & co-evolved \\
\hline Myrmica rubra & 1 & 0 & 0 & 12 & 7 & 0 & host & co-evolved \\
\hline Pognomyrmex barbatus & 1 & 0 & 0 & 11 & 13 & 6 & non-host & not co-evolved \\
\hline Aphaenogaster senilis & 1 & 1 & 0 & 11 & 11 & 1 & non-host & not co-evolved \\
\hline Messor barbarus & 1 & 0 & 0 & 13 & 4 & 3 & non-host & not co-evolved \\
\hline Tetramorium bicarinatum & 1 & 1 & 1 & 11 & 6 & 6 & non-host & not co-evolved \\
\hline Solenopsis invicta & 1 & 0 & 0 & 2 & 2 & 0 & host & co-evolved \\
\hline Wasmannia auropunctata & 1 & 1 & 1 & 8 & 2 & 0 & non-host & not co-evolved \\
\hline Ectatomma ruidum & 1 & 2 & 1 & 9 & 12 & 0 & non-host & not co-evolved \\
\hline Gnamptogenys striatula & 1 & 1 & 0 & 9 & 15 & 1 & non-host & not co-evolved \\
\hline Platythyrea punctata & 1 & 1 & 2 & 9 & 0 & 0 & non-host & not co-evolved \\
\hline Diacamma ceylonese & 1 & 1 & 0 & 12 & 2 & 0 & non-host & not co-evolved \\
\hline Dinoponera quadriceps & 1 & 1 & 1 & 10 & 5 & 0 & non-host & not co-evolved \\
\hline Harpegnathos saltator & 1 & 2 & 0 & 12 & 15 & 0 & non-host & not co-evolved \\
\hline Pachycondyla apicalis & 1 & 0 & 1 & 5 & 1 & 0 & non-host & not co-evolved \\
\hline Pachycondyla goeldi & 1 & 1 & 1 & 1 & 0 & 0 & non-host & not co-evolved \\
\hline Pachycondyla inversa & 1 & 1 & 0 & 10 & 3 & 0 & non-host & not co-evolved \\
\hline Pachycondyla villosa & 1 & 1 & 0 & 16 & 28 & 1 & non-host & not co-evolved \\
\hline Myrmecia gulosa & 1 & 1 & 0 & 8 & 0 & 0 & non-host & not co-evolved \\
\hline Iridomyrmex purpureus & 1 & 2 & 0 & 14 & 3 & 0 & non-host & not co-evolved \\
\hline Iridomyrmex nitidiceps & 1 & 3 & 0 & 11 & 11 & 2 & non-host & not co-evolved \\
\hline Linepithema humile & 1 & 4 & 0 & 13 & 3 & 4 & non-host & not co-evolved \\
\hline Nothomyrmecia macrops & 1 & 1 & 0 & 13 & 7 & 0 & non-host & not co-evolved \\
\hline Camponotus fellah & 1 & 0 & 1 & 7 & 1 & 1 & non-host & not co-evolved \\
\hline Camponotus floridanus & 1 & 0 & 0 & 11 & 17 & 3 & non-host & not co-evolved \\
\hline Camponotus vagus & 1 & 1 & 0 & 12 & 33 & 6 & non-host & not co-evolved \\
\hline Cataglyphis bombycinus & 1 & 1 & 0 & 10 & 17 & 2 & non-host & not co-evolved \\
\hline Cataglyphis cursor & 1 & 3 & 0 & 7 & 11 & 0 & non-host & not co-evolved \\
\hline Cataglyphis floricola & 1 & 3 & 0 & 14 & 12 & 0 & non-host & not co-evolved \\
\hline Cataglyphis hispanicus & 1 & 2 & 1 & 12 & 5 & 0 & non-host & not co-evolved \\
\hline Cataglyphis humeya & 1 & 2 & 1 & 7 & 7 & 0 & non-host & not co-evolved \\
\hline Cataglyphis iberica & 1 & 0 & 0 & 8 & 6 & 0 & non-host & not co-evolved \\
\hline Cataglyphis ibericus & 1 & 5 & 0 & 14 & 21 & 4 & non-host & not co-evolved \\
\hline Cataglyphis niger & 1 & 0 & 0 & 7 & 6 & 0 & non-host & not co-evolved \\
\hline Cataglyphis rosenhaueri & 1 & 3 & 1 & 15 & 30 & 6 & non-host & not co-evolved \\
\hline Cataglyphis velox & 1 & 1 & 1 & 11 & 9 & 0 & non-host & not co-evolved \\
\hline Formica aquilonia & 1 & 1 & 0 & 12 & 6 & 0 & host & co-evolved \\
\hline Formica candida & 1 & 1 & 1 & 8 & 0 & 0 & non-host & not co-evolved \\
\hline Formica cinerea & 1 & 1 & 0 & 7 & 2 & 0 & non-host & not co-evolved \\
\hline Formica cunicularia & 1 & 3 & 0 & 12 & 9 & 0 & host & co-evolved \\
\hline Formica exsecta & 1 & 1 & 0 & 7 & 0 & 0 & non-host & non-host \\
\hline
\end{tabular}


Table 1. (Cont.)

\begin{tabular}{|c|c|c|c|c|c|c|c|c|}
\hline Species & $n$ alkanes & alkenes & dienes & monomethylalkanes & dimethylalkanes & trimethylalkanes & ant status & co-evolved? \\
\hline Formica fucsa & 1 & 1 & 0 & 13 & 10 & 0 & non-host & non-host \\
\hline Formica glacialis & 1 & 1 & 0 & 4 & 1 & 0 & non-host & non-host \\
\hline Formica glava & 0 & 0 & 0 & 6 & 5 & 0 & non-host & non-host \\
\hline Formica japonica & 1 & 2 & 0 & 4 & 0 & 0 & host & co-evolved \\
\hline Formica lemani & 1 & 1 & 0 & 7 & 0 & 0 & host & co-evolved \\
\hline Formica lugubris & 1 & 1 & 0 & 12 & 6 & 0 & host & co-evolved \\
\hline Formica montana & 1 & 1 & 0 & 0 & 0 & 0 & non-host & non-host \\
\hline Formica occulta & 0 & 0 & 0 & 11 & 21 & 0 & host & co-evolved \\
\hline Formica polyctena & 1 & 1 & 0 & 12 & 7 & 0 & host & co-evolved \\
\hline Formica pratensis & 1 & 1 & 0 & 12 & 5 & 0 & host & co-evolved \\
\hline Formica rufa & 1 & 1 & 0 & 12 & 4 & 0 & host & co-evolved \\
\hline Formica rufibarbis & 1 & 0 & 0 & 12 & 11 & 0 & host & co-evolved \\
\hline Formica sanguinea & 1 & 1 & 0 & 13 & 5 & 0 & dulotic & co-evolved \\
\hline Formica selysi & 1 & 1 & 3 & 5 & 1 & 0 & non-host & non-host \\
\hline Formica truncorum & 1 & 1 & 0 & 12 & 5 & 0 & non-host & non-host \\
\hline Formica uralensis & 1 & 1 & 0 & 12 & 7 & 1 & non-host & non-host \\
\hline Lasius fuliginosus & 1 & 1 & 0 & 8 & 1 & 0 & non-host & non-host \\
\hline Lasius sakagonii & 1 & 1 & 0 & 4 & 3 & 0 & non-host & non-host \\
\hline Lasius niger & 1 & 1 & 0 & 5 & 9 & 0 & non-host & non-host \\
\hline Polyergus breviceps & 1 & 0 & 0 & 1 & 0 & 0 & dulotic & co-evolved \\
\hline Polyergus rufescens & 1 & 3 & 0 & 11 & 6 & 0 & dulotic & co-evolved \\
\hline Proformica longiseta & 1 & 0 & 0 & 9 & 9 & 0 & host & co-evolved \\
\hline Rossomyrmex minuchae & 1 & 0 & 0 & 9 & 9 & 0 & dulotic & co-evolved \\
\hline
\end{tabular}

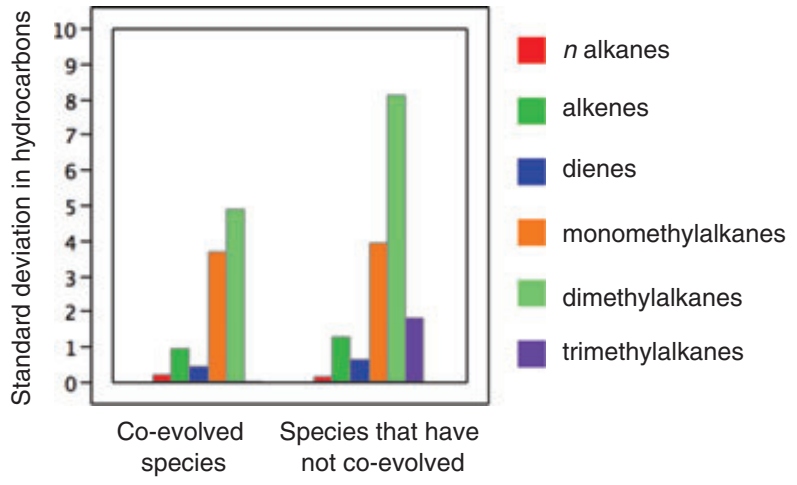

Fig. 2. The relationship between co-evolution and the extent of diversity in different components of the ant cuticular hydrocarbon signature. 'Co-evolved species' includes 26 species of host and parasitic ant, 'species that have not co-evolved' includes 52 ant species not currently described as host to a brood parasite of any sort (see text and Table 1 for details). For each species, Martin \& Drifjhout (2009) describe the number of different sorts of hydrocarbon present in the cuticle. The standard deviation of this number, calculated using the species in each category, is shown on the $y$-axis.

experimental work shows that an increase in shell strength alone is not sufficient to prevent egg rejection, although it can reduce the incidence of egg rejection when the parasitic egg mimics the host clutch (Antonov et al., 2008a,b).

What is the consequence of parasite shell thickening for hosts? The main effect is that hosts find it harder to remove alien eggs from their clutch without damaging their own eggs in the process (Antonov et al., 2006; Rohwer, Spaw \& Røskaft, 1989). Selection then favours hosts that can minimize damage to their fitness, which they achieve in a number of different ways.

One possibility is that they may thicken their own eggshells, so that host eggs are no longer collaterally damaged during puncture rejection of the parasitic egg. This is the strategy adopted by the many hosts of the diederik cuckoo, whose shell thickness covaries with that of their particular cuckoo race (Spottiswoode, 2010). At some point, presumably, directional co-evolution on shell thickness must be constrained by the necessity for chicks within the fortress egg to break free at hatching (Honza et al., 2001), and there is a suggestion that this upper limit may have been reached in Southern red bishop Euplectes orix hosts (Spottiswoode, 2010).

Magpie Pica pica hosts of the great-spotted cuckoo appear to use a different strategy, offsetting the costs of egg damage by increasing their clutch size. Magpie populations in sympatry with the cuckoo lay more eggs than unparasitized populations (Soler et al., 2001), and seem to pay for the increase in clutch size by laying smaller eggs.

Alternatively, hosts may choose to desert the entire clutch rather than attempt to extract the parasitic egg alone (Antonov et al., 2006), a strategy that is pursued by the yellow warbler Dendroica petechia (Guigueng \& Sealy, 2010) and other hosts of the brown-headed cowbird Molothrus ater that have a long history of co-evolution with this brood parasite (Hosoi \& Rothstein, 2000). The greater the loss in fecundity sustained by 'old cowbird hosts' as a consequence of parasitism, the more likely the incidence of clutch desertion (Hosoi \& Rothstein, 2000). Nevertheless, defence by clutch desertion is very costly because hosts lose all their own young as well as rejecting the cowbird egg. Furthermore, even among the most discriminating cowbird hosts, at least 
Table 2. The results of a Levene's test comparing variance in the number of different hydrocarbon types in species that have co-evolved as a result of social parasitism with species that have no (known) history of co-evolution with brood parasites. Statistically significant differences are shown in bold and are caused by lower variances in the 'co-evolved' species group (see Fig. 2)

\begin{tabular}{lcc}
\hline \hline Hydrocarbon type & $F_{1,76}$ & $P$ \\
\hline$n$ alkane & 1.00 & 0.32 \\
Alkene & 0.45 & 0.50 \\
Diene & 2.94 & 0.091 \\
Monomethylalkane & 0.129 & 0.72 \\
Dimethylalkane & $\mathbf{5 . 0 9}$ & $\mathbf{0 . 0 2 7}$ \\
Trimethylalkane & $\mathbf{2 9 . 4 0}$ & $<\mathbf{0 . 0 0 0 1}$ \\
\hline \hline
\end{tabular}

$30 \%$ of parasitized clutches continue to be tended by hosts (Hosoi \& Rothstein, 2000). Consequently, these defences against parasitism are not sufficient alone to protect host fecundity and strategies of tolerance have been selected to further safeguard host reproductive success. For example, comparative analyses show that brown-headed cowbird host species typically lay smaller clutches than their nonparasitized counterparts and produce more clutches during the breeding season (Hauber, 2003). Presumably by laying fewer eggs each time they breed, hosts risk wasting fewer young of their own if they desert a parasitized clutch or through competition with the cowbird after hatching, if they initially accept the cowbird egg.

The general pattern that emerges is that there is a negative correlation among avian brood parasite hosts between investment in resistance and investment in tolerance, just as experimental work has found in other victim-exploiter systems (e.g. Best, White \& Boots, 2008; Fineblum \& Rauscher, 1995; Råborg, Sim \& Read, 2007). Cuculus canorus and Chrysococcyx caprius hosts respond to eggshell thickening in the parasite by investing exclusively in more sophisticated resistance strategies, whereas magpie hosts of Clamator glandarius show some resistance through egg rejection but have also adjusted their life histories to tolerate the costs of parasitism. Molothrus ater hosts seem to be the most tolerant and they reject the parasite egg only by rejecting their entire clutch as well. For parasites, the principal correlate of this negative relationship is varying selection for egg mimicry. Since Cuculus canorus and Chrysococcyx caprius hosts continue to be strongly discriminatory, these cuckoos lay eggs that are sophisticated mimics of the host clutch. Clamator glandarius hosts are more weakly discriminating and this cuckoo lays an egg which only approximately mimics those of its host (Soler et al., 2001) whereas Molothrus ater hosts are the least discerning of all, and apparently use cues other than egg colour to identify a parasitized clutch (Hill \& Sealy, 1994). These parasites exhibit no egg mimicry at all (Davies, 2000).

\section{(3) Do co-evolutionary arms races follow predictable trajectories?}

Despite their considerable taxonomic disparity, there is a striking degree of convergence in the way that co-evolution proceeds between brood parasites and their hosts in insects and birds. In each system, hosts employ two principal lines of defence: physical attack on the front line followed by recognition systems for identifying any parasites that manage to penetrate the nest. Parasites respond to front-line defences with improved armoury or with increased furtiveness, and the latter seems more likely to result in successful parasitism. To evade host recognition systems, parasites may mimic host signatures either before or after parasitism; they can become cryptic, or they can risk recognition by fighting host rejection attempts. Becoming cryptic seems most likely to guarantee the parasite victory in the ensuing arms race because hosts are constrained in their ability to then expose and detect the near-invisible parasite.

In several systems, parasites seem to employ multiple strategies for evading recognition and resisting rejection (see also Section III.2). Perhaps this is because different counter-strategies are acquired at different stages of coevolution, but persist today because together they increase the chance of successful parasitism. For example, parasites may initially be generalists that acquire host-specific signatures after parasitism, but through counter-selection by hosts may subsequently evolve genetic signatures expressed before parasitism. Likewise, among the insects, selection to become chemically insignificant may have facilitated the ability to acquire host hydrocarbon signatures after parasitism. In general, there is little indication of an intrinsic trade-off in the parasite between different forms of counter-adaptation. Instead, the blend of counter-adaptations expressed in the parasite reflects a response to the particular blend of defences expressed in the host.

\section{OUTCOMES OF GO-EVOLUTION}

Having identified ways in which co-evolution might proceed, we now turn to the second aim of this review, namely to identify common outcomes of co-evolution. Four alternatives are apparent and they cut across the specific co-evolutionary arms races identified above.

\section{(1) Successful resistance by hosts}

The first possible outcome is that the host successfully resists invasion by the parasite, and ceases to be exploited in future interactions. This endpoint can most readily be identified when resistance is due to effective front-line defences. For example, Polistes dominulus foundresses are now so large and aggressive that they can consistently defend their nests from attack by the brood parasite $P$. sulcifer and parasitism is rarely seen (Ortolani \& Cervo, 2010). In Northern Italy, Formica rufibarbis host ant nests are similarly capable of resisting parasite attack. Here, colonies can successfully resist invasion by the slave-making ant Polyergus rufescens because workers ruthlessly and relentlessly attack any intruding slavemaker queen to prevent her from reaching the resident queen in the brood chamber. The workers' defence of the colony is so 
vicious that the slave-making queen commonly dies from her injuries and parasitism of this host population seldom occurs (Mori et al., 1995).

Experimental evidence indicates that defences associated with host recognition systems have also enabled avian hosts to defeat parasites once and for all. Work on a potential host species in sympatry with the little cuckoo Cuculus poliocephalus suggests that signature diversification has given this host the advantage over the cuckoo. The yellow-browed leaf warbler Phylloscopus humei lays eggs that are uniform in size within clutches yet highly variable among clutches. High interclutch variation in egg size coupled with rejection of any eggs that are discordant in size with the rest of the clutch, seems to have enabled this host to escape the parasite altogether (Marchetti, 2000). Further indirect evidence that avian host recognition systems can defeat cuckoos is provided by the error-free rejection of oddly marked experimental eggs by hosts that are currently not exploited by brood parasites. Perhaps the best evidence here comes from work on Fringilla species. The chaffinch $F$. coelobs is no longer routinely parasitized by the common cuckoo, and brood parasitism of the brambling $F$. montifringilla is now rare in Fennoscandia (Vikan et al., 2010). Nevertheless, both species still exhibit fine egg discrimination skills that cannot be attributed to intraspecific brood parasitism. Furthermore, work on museum specimens has identified a Fringilla gens of the common cuckoo, which shows a very high level of mimicry of brambling eggs in particular (Moksnes et al., 1995; Stoddard \& Stevens, 2010). Together, the evidence suggests historical brood parasitism of the chaffinch, which no longer persists owing to the sophisticated egg discrimination behaviour exhibited by this host species (Stokke et al., 2002). The common cuckoo's exploitation of the brambling seems to be moving towards the same endpoint (Vikan et al., 2010).

\section{(2) Further resistance by hosts: defence portfolios}

In many cases, host defences are not sufficiently robust to deter the parasite completely and the victimisation of some host individuals in the population is commonly seen. How do hosts respond once one line of resistance becomes permeable to parasitism? One general outcome is to mount further lines of resistance, so that hosts possess a portfolio of defences against the parasite, deployed in hierarchical sequence (Britton, Planque \& Franks, 2007; Langmore \& Kilner, 2010; Planque et al., 2002; Svennungsen \& Hølen, 2010; Welbergen \& Davies, 2009) in much the same way as prey species use multiple means to protect themselves from predators (Ruxton, Sherratt \& Speed, 2004).

Recent work suggests that the depth of these portfolios might depend on the strength of selection exerted by each successive line in the defence hierarchy on the next. For example, theoretical work shows that egg rejection can be adaptive even when hosts are unable correctly to identify the parasitic egg in their clutch and just randomly choose one for removal, as long as hosts are certain they have been parasitized (Svennungsen \& Holen, 2010). By providing a reliable cue for parasitism, interactions between hosts and parasites on the front line can therefore directly select for egg rejection behaviour, long before any egg recognition systems have evolved (Svennungsen \& Holen, 2010). Once established, egg rejection behaviour could then select for an egg recognition system in the host because any individual that could specifically target a foreign egg for rejection, rather than simply removing an egg at random, would gain an immediate advantage. Host recognition systems could in turn select for elaborate host egg signatures, because hosts are then more likely to identify alien eggs for rejection. Consistent with this idea, empirical work shows that when selection by host recognition systems on egg morphology is relaxed (because hosts cease to reject eggs in the absence of cuckoos) their egg signatures rapidly lose their complexity (Lahti, 2005, 2006). Exposure to brood parasites thus results in changes in host behaviour which then subject other parts of the host phenotype to novel, recurrent selection regimes for further defences, and this can elaborate the host's defence portfolio. As long as there is sufficient selection for further host defences (see Sections III.3 and III.4), coupled with sufficient genetic variation in the host for selection to act upon and sufficient time for selection to act, defence portfolios could, in principle, become extremely complex (a process we might call 'strategy-facilitation' to complement the opposing process of 'strategy-blocking' previously identified by Britton et al., (2007), and described below).

Indeed, a striking parallel in work on both insect and avian brood parasites is the discovery that host defence portfolios can show remarkable depth, much more than theoretical analyses originally suggested was possible (Gladstone, 1981; Lotem, 1993), because they include the recognition and rejection of hatched offspring. For example, in the insects, Temnothorax spp. workers, enslaved by Protomognathus americanus, fight back by selectively destroying the slavemaking pupae in their care. As a result, $P$. americanus colonies are unusually small for a slavemaker, and are less effective at conducting destructive slave raids on neighbouring Temnothorax spp. colonies (Achenbach \& Foitzik, 2009). Slave rebellion benefits the host, not through any improvement in direct fitness but because Temnothorax spp. populations are highly kin-structured, and relatives at neighbouring freeliving colonies are spared from attack by the slavemaker as a consequence. Similar post-hatching defences are seen in the interactions between some Chalcites cuckoos and their hosts. Horsfield's bronze-cuckoo eggs closely resemble host superb fairy-wren Malurus cyaneus eggs but these hosts now possess poor egg discrimination skills and have never been observed to reject a cuckoo egg (Langmore et al., 2003, 2005). However, superb fairy-wrens are adept at recognizing cuckoo nestlings and roughly $40 \%$ are abandoned by hosts shortly after hatching and left to starve (Langmore et al., 2009a, 2003). Gerygone spp. hosts of the little bronze-cuckoo are similarly defenceless at the egg stage, having been beaten by an apparently cryptic cuckoo egg (Langmore et al., 2009b). Nevertheless, these hosts are able to counter-attack at the nestling stage with a unique line of defence: they grasp the newly hatched cuckoo chick and fling it from the nest before 
resuming incubation of their unhatched eggs and, eventually, tending an unparasitized brood (Sato et al., 2010; Tokue \& Ueda, 2010).

In all three cases, in response to discrimination by hosts, a mimicry-based arms race is clearly starting to play out after hatching. In the insects, analyses of cuticular hydrocarbons reveal distinct differences between host and parasite pupae, which no doubt enables recognition by the slaves. Nevertheless, parasitic pupae are less likely to be rejected when introduced into sympatric host colonies than allopatric nests of the same host species, suggesting there has been some local counter-adaptation by the parasite (Achenbach, Witte \& Foitzik, 2010). Similarly, in the Horsfield's bronze-cuckoo, parasitic offspring mimic the begging calls produced by host young (Langmore et al., 2008), while little bronze-cuckoo nestlings are almost perfect visual mimics of Gerygone magnirostris host chicks (Langmore et al., 2011 ; Sato et al., 2010).

The avian examples of nestling rejection illustrate a further way in which the different lines of resistance in the defence portfolio are interdependent. We have already seen how mechanisms of parasite resistance can select further lines of defence later in the breeding cycle ('strategy-facilitation'). The nestling rejection examples show how, once in place, a highly effective line of resistance (e.g. chick rejection) can relax selection on a less effective form of defence (e.g. egg rejection) to the point that it decays completely (Lahti et al., 2010; Langmore \& Kilner, 2009), a process known as 'strategy-blocking' (Britton et al., 2007). The relative strength of strategy-facilitation versus strategy-blocking will potentially determine how many different lines of defence hosts mount against parasites (see also Soler et al., 1999a). For example, empirical observations suggest that when parasites are especially virulent, strategy-facilitation is likely to outweigh strategy-blocking to promote the complexity of defence portfolios. The most elaborate portfolios of avian host defences are seen among hosts of the Cuculus, Chrysococcyx and Chalcites cuckoos. Nestlings of these brood parasites are ruthlessly destructive, killing all host young within hours of hatching by evicting them from the nest (Davies, 2000) and parasitism rates can be very high (Langmore \& Kilner, 2007; Lawes \& Kirkman, 1996; Moskat \& Honza, 2002; Sato et al., 2010). Perhaps their hosts have no option but to deploy multiple lines of resistance to parasitism because the damage to host fecundity that parasites would otherwise cause is so great (Servedio \& Hauber, 2006). If this hypothesis is correct, then we should expect to see the most extensive defence portfolios among other hosts that are victims of the most virulent brood parasites.

The slave rebellion exhibited by Temnothorax spp. also identifies otherwise cryptic benefits to hosts of maintaining multiple lines of resistance. It is tempting to speculate that the marked kin structure of superb fairy-wren host populations (Double et al., 2005) explains why this host has escalated its defences to include chick rejection (Langmore et al., 2003) when most hosts of the equally virulent common cuckoo have not (e.g. Davies, 2000, but see Grim, 2007).
In kin-structured populations, investment in host defences is akin to investment in social immunity (Cotter \& Kilner, 2010), in that relatives gain from defences mounted through the associated reduction in the force of parasitism (Frank, 1998). If this hypothesis is correct, then the benefits of investing in continued resistance should be greater in kinstructured host populations than otherwise, and defence portfolios correspondingly more diverse.

Finally, in many instances, the co-evolution of a broodparasite-host pair will be complicated by the presence of multiple sympatric host species (Brandt et al., 2005a; Davies, 2000; Thompson, 2005). In principle, this could provide another benefit for investment in further lines of resistance because there is an incentive for each host species to win apparent competition with other sympatric host species for enemy-free space (Begon, Harper \& Townsend, 1996). It would be interesting to develop formal theoretical analyses of this problem for empiricists to test in future work.

\section{(3) Acceptance of the parasite}

Interactions between brood parasites and their hosts yield a curious blend of the exquisitely adaptive and (seemingly) absurdly maladaptive. Having dealt with examples of the former type, we now turn to outcomes of co-evolution that are firmly in the latter category, such as the acceptance of eggs that are entirely unlike the host clutch (e.g. Davies, 2000; Langmore et al., 2009b) or the prolonged provisioning of a monstrous alien young by hosts (e.g. Barbero et al., 2009; Cervo, 2006; Kilner, Noble \& Davies, 1999). One explanation for the persistence of these behaviours is that they are not adaptive for the host, but the consequence of 'evolutionary lag' or 'constraint'. The host would benefit by rejecting the parasitic offspring but there has been insufficient time, or insufficient variation upon which selection can act, for efficient rejection mechanisms to evolve. These are not descriptions of co-evolutionary outcomes, but rather the starting point from which co-evolution might proceed. Evolutionary lag is classically invoked to explain why dunnocks Prunella modularis fail to recognize odd-looking common cuckoo eggs in their nest (Brooke \& Davies, 1988) and might also be invoked to explain why some species have relatively thin defence portfolios, comprising few lines of defence. Too brief a history of interaction with brood parasites specifically explains why new cowbird hosts are defenceless in the face of extreme exploitation (Hosoi \& Rothstein, 2000) while lack of sufficient genetic variation seemingly explains the absence of defences among some hosts of slave-making ants (Brandt et al., 2005a). However, the weakness of the evolutionary lag hypothesis is that it is not easily falsified, given our current understanding of the genetics underpinning adaptations in nature. It is not always clear how much time is required for genetic adaptations to arise and spread (except on very short timescales e.g. Robert \& Sorci, 1999), nor how much genetic variation is necessary for adaptations to evolve.

A second explanation, 'the evolutionary equilibrium hypothesis' (Brooker \& Brooker, 1996; Davies \& Brooke, 
1989; Lotem, Nakamura \& Zahavi, 1995; Marchetti, 1992), more interestingly suggests that acceptance is an adaptive strategy for hosts when the costs of rearing a parasite are, on average, lower than any recognition costs. Variation in the ratio of these two costs thus explains why populations of the same species become more inclined to accept brood parasites when parasite pressure, and hence the average of cost of parasitism, declines (e.g. Brooke et al., 1998; Davies et al., 1996; Lotem et al., 1995). It also explains why naïve individuals are more likely to accept parasites than experienced breeders, all else being equal, because they have yet to develop the error-free recognition systems that are honed by breeding experience (e.g. Langmore et al., 2009a; Lotem, Nakamura \& Zahavi, 1992; Lotem et al., 1995).

The same argument can be extended in two different ways to explain the lack of depth in some host defence portfolios and, in particular, why some hosts accept parasitic offspring after hatching even though they exhibit sophisticated powers of discrimination earlier in the breeding cycle (e.g. Davies, 2000; Martin et al., 2010a; Schönrogge et al., 2006). The first extension of this idea focuses on recognition costs. It assumes that hosts learn to recognize their own young during their first encounter with offspring, and so are vulnerable to misimprinting on the parasite, especially if it has killed all the host young. A misimprinted host will suffer very high costs because it will reject all subsequent broods of their own. As a result, the costs of learning to recognize offspring are always greater than the benefits, and acceptance is the better strategy (Lotem, 1993). There is now experimental evidence for misimprinting in this way in an intraspecific brood parasite, the American coot Fulica americana (Shizuka \& Lyon, 2010), and it could apply in principle to Polistes wasps, where foundresses will never encounter their own larvae before the parasite hatches (Cervo, 2006). Nevertheless, it seems unlikely to apply to social insect species where many individuals, with contrasting larval rearing experiences, collectively tend the brood (Johnson et al., 2011). Furthermore, we know that in other avian species there are other, less error-prone ways in which hosts can recognize their young (Langmore et al., 2009a), and that the costs of chick recognition and rejection do not always prevent the evolution of evictor cuckoo-chick rejection (e.g. Langmore et al., 2009a, 2003; Sato et al., 2010; Tokue \& Ueda, 2010).

Acceptance of cuckoo nestlings might instead be the consequence of robust lines of defence mounted earlier in the breeding cycle (Britton et al., 2007; Davies \& Brooke, 1989; Grim, 2006), an idea that focuses on variation in the costs of parasitism, rather than costs associated with recognition. The argument here is that effective rejection of cuckoo eggs prevents the evolution of cuckoo chick recognition because the cuckoo nestling is such a rare enemy that the benefits of discriminating against it are easily outweighed by any associated recognition costs. Numerical solutions of theoretical analyses show that this argument can work hypothetically (Britton et al., 2007) and it fits the empirical observation that cuckoo chick rejection is typically observed among hosts that lack any egg recognition skills
(Langmore et al., 2009a, 2003; Sato et al., 2010; Tokue \& Ueda, 2010). Nevertheless, recent theoretical work shows that cuckoo egg rejection does not automatically prevent the evolution of cuckoo chick rejection (Ø. H. Hølen, personal communication) and there are some cuckoo (Grim, 2007) and slavemaker ant hosts (Achenbach \& Foitzik, 2009) where both lines of defence are seen. The widespread acceptance of cuckoo nestlings, and of parasitic larvae, therefore currently lacks a general adaptive explanation (Kilner, 2010).

\section{(4) Tolerance of the parasite}

In some cases, hosts not only concede to the parasite, and accept it in their nests, but also make adjustments to their life history (or other traits) to minimize the negative effects of parasitism on their fitness (Svensson \& Råborg, 2010). It is these adjustments in host life history (or other characteristics) that distinguish strategies of tolerance from those of acceptance. Although tolerance is best known from hosts of plant pathogens, it is increasingly evident among brood parasite hosts as well. The net winner in such a coevolutionary outcome is, of course, the parasite who can persist in exploiting its host without sustaining a substantial initial outlay on overcoming host defences (Svensson \& Råborg, 2010). Tolerance is practised by hosts of avian brood parasites because there is evidence that both Clamator glandarius hosts and Molothrus ater hosts have adjusted aspects of their life histories to accommodate parasites that evade host rejection (discussed in detail in Section II.2d). Two examples from insects further illustrate how tolerance can result from a breakdown in front-line defences.

Proformica longiseta ant hosts of the slavemaker Rossomyrmex minuchae appear to tolerate their parasite because the costs of mounting front-line defences are far more substantial than passively accommodating the parasite (Zamora-Muñoz et al., 2003). When $R$. minuchae secondarily raids host colonies for pupae it is extremely aggressive, particularly so if hosts attempt to defend themselves, to the extent that few such defended host colonies survive a raid. Counterintuitively, however, if hosts put up no defences to the raiding slavemaker, they lose some brood but the workers sustain fewer injuries and the colony survives the assault. The host's co-evolved response to raids by the slavemakers is therefore to show tolerance rather than resistance (ZamoraMuñoz et al., 2003). To prevent costly attacks being launched on incoming parasites, there has even been selection on hosts to mimic the parasite's hydrocarbon signature so that raiding parasites are no longer regarded as colony intruders by host workers, and can wander in and out at will, free from host attack (Errard et al., 2006).

A failure in front-line defences has also selected tolerance in Temnothorax longispinus hosts of Protomognathus americanus slavemakers, but for a different reason. In this host-parasite pairing, there is geographical variation in the harm that the slavemaker inflicts on hosts during raids, for reasons that are still being elucidated. In New York (NY), for example, the slavemaker is especially virulent whereas in West Virginia (WV), slavemakers are far less harmful to their hosts (Foitzik 
et al., 2001; Herbers \& Foitzik, 2002). Host defences against slave raids vary correspondingly in their vigour, being much more robust in NY than in WV (Foitzik et al., 2001). Nevertheless, parasite pressure remains considerably greater in NY than WV, and hosts in NY have adapted their life history and demography to tolerate the greater harm to their fitness inflicted by the parasite, producing more dispersing sexuals than the WV hosts and more females than males in general, presumably so as to replace brood routinely lost to the slavemaker (Foitzik \& Herbers, 2001). Although elegant cross-fostering experiments in the field have shown that tolerance of this sort is the result of phenotypic plasticity, they also suggest that the extent of phenotypic plasticity has evolved as a consequence of parasitism because the reaction norm in the NY population is steeper than the reaction norm in the WV population (Foitzik, Achenbach \& Brandt, 2009). So once again, tolerance appears to be a co-evolved consequence of a failure to repel parasites at the front line.

\section{(5) Do co-evolutionary arms races yield predictable outcomes?}

Co-evolutionary arms races between brood parasites and their hosts can yield four possible outcomes for the host (successful resistance, the evolution of defence portfolios, acceptance, and tolerance; cf. Davies, 2000, p.119). Empirical work suggests that the particular outcome is not necessarily contingent on the type of preceding co-evolutionary arms race (as identified in Section II). Furthermore, multiple concurrent outcomes to parallel arms races are evident in some cases, indicating that the different possible outcomes are not necessarily mutually incompatible (cf. Svensson \& Råborg, 2010). So why do some hosts mount further lines of resistance to parasitism when one line of defence is breached, while others accept or tolerate the parasite? Empirical work to date is consistent with the theoretical suggestion that strategies of acceptance or tolerance can be adaptive when their payoffs exceed those connected with mounting further lines of resistance (Sections III.3 and III.4). In general, it is adaptive for hosts to accept a parasite when resistance carries high costs, perhaps because host recognition systems are relatively unsophisticated or because the host clutch is inadequately protected from the physical damage associated with the rejection of foreign eggs. Acceptance is therefore determined by qualities intrinsic to the host.

By contrast, a strategy of tolerance is seemingly imposed on hosts by parasites. Among birds, for example, tolerance is adaptive when parasites threaten potentially resistant hosts with fitness sanctions by making egg rejection too costly with a specially thickened shell (described in Section II.2d). Furthermore, field experiments suggest that adult brown-headed cowbirds (Hoover \& Robinson, 2007) and great-spotted cuckoos (Soler et al., 1999b, 1995) punish hosts that have rejected a parasitic egg by destroying their nests, so forcing them to tolerate a parasitized clutch the next time they breed or else risk complete nest failure again. As long as parasites reward hosts that tolerate alien offspring by letting them rear some young of their own (Pagel, Møller \& Pomiankowski, 1998), nest destruction by adult parasites can increase the costs of host resistance to the extent that tolerance becomes the economically superior alternative (Robert et al., 1999). We see exactly the same pattern in insect examples, with tolerance evolving when hosts cannot afford simply to resist virulent attacks by the parasite. In the case of Proformica longiseta, acts of resistance are themselves so costly as to be uneconomic, just as in the two avian studies. In Temnothorax longispinus, resistance is not necessarily costly, just comparatively ineffective at containing the damage incurred by the virulent slavemaker. In this situation, tolerance has become part of a mixed strategy to defend the host's fecundity, rather than an alternative to resistance. In short, the particular co-evolutionary outcome depends to a large degree on whether the host or the parasite controls the co-evolutionary trajectory, rather than on the specific nature of the co-evolutionary arms race. When traits in the parasite inflate the cost of host resistance, by retaliation or retribution for example, tolerance is the more likely outcome than acceptance.

\section{GONGLUSIONS}

(1) Despite their considerable taxonomic disparity, there are striking parallels in the way that co-evolution proceeds between brood parasites and their hosts in the insects and the birds.

(2) Five types of co-evolutionary arms race can be identified from the empirical literature, which are common to both systems. These are: (a) directional co-evolution of weaponry and armoury; (b) furtiveness in the parasite countered by strategies in the host to expose the parasite; (c) specialist parasites mimicking hosts who escape by diversifying their genetic signatures; (d) generalist parasites mimicking hosts who escape by favouring signatures that force specialization in the parasite; and (e) parasites using crypsis to evade recognition by hosts who then simplify their signatures to make the parasite more detectable. Arms races $\mathrm{a}$ and $\mathrm{c}$ are well characterized in the theoretical literature on co-evolution, but the other types have received little or no formal theoretical attention.

(3) Evidence from the better studied brood parasites and their hosts suggests that several types of co-evolutionary arms race, each focused on different modes of host defence, can play out concurrently between a single host and its brood parasite. Nevertheless, there is considerable interspecific variation in the complexity and depth of host defence portfolios. Whether this variation is adaptive, or merely reflects evolutionary lag, is unclear. We suggest an adaptive explanation for this variation, which centres on the relative strength of two opposing processes: strategy-facilitation, in which each line of host defence promotes the evolution of another form of resistance, and strategy-blocking, in which one line of defence may relax selection on another so completely that the former causes the latter to decay. 
When strategy-facilitation outweighs strategy-blocking, hosts are likely to possess complex defence portfolios.

(4) Empirical work suggests that hosts are doomed to lose arms races $b$ and e to the parasite, in the sense that parasites typically evade any host defences and successfully parasitise the nest. Nevertheless hosts may beat parasites completely when the co-evolutionary trajectory follows arms race a, c or d.

(5) Each of five types of co-evolutionary arms race has one of four potential outcomes for the host. These are: (1) successful resistance; (2) the evolution of defence portfolios; (3) acceptance of the parasite; and (4) tolerance of the parasite (i.e. acceptance of the parasite in conjunction with new strategies in the host to minimize the damage that parasites inflict on host fecundity).

(6) When hosts control the co-evolutionary trajectory, empirical work suggests that outcomes $1-3$ are more likely, whereas outcome 4 results from parasitic control of the co-evolutionary trajectory. In future work, it would be interesting to use comparative analyses to evaluate the extent to which co-evolutionary outcomes are determined by hosts or their brood parasites.

\section{AGKNOWLEDGEMENTS}

This review was inspired by an invitation to R.M.K. from Ben Oldroyd to speak in a symposium at the IUSSI in Copenhagen in 2010. N.E.L. was supported by an ARC Australian Research Fellowship and our long-term research on the Chalcites cuckoos and their hosts has been supported by the Australian Research Council, The Leverhulme Trust and The Royal Society. We thank Øistein Holen, Claire Spottiswoode, Cassie Stoddard and Nick Davies for discussion and two anonymous referees for their comments on the manuscript.

\section{REFERENCES}

Achenbach, A. \& Foitzik, S. (2009). First evidence for slave rebellion: enslaved ant workers systematically kill the brood of their social parasite Protomognathus americanus. Evolution 63, 1068-1075.

Achenbach, A., Witte, V. \& Foitzik, S. (2010). Brood exchange experiments and chemical analyses shed light on slave rebellion in ants. Behavioral Ecology 21, 948-956.

Akino, T., Knapp, J. J., Thomas, J. A. \& Elmes, G. W. (1999). Chemical mimicry and host specificity in the butterfly Maculinea rebeli, a social parasite of Myrmica any colonies. Proceedings of the Royal Society B 266, 1419-1426.

Als, T. D., Vila, R., Kandul, N. P., Nash, D. R., Yen, S. H., Hsu, Y. F., Mignault, A. A., Boomsma, J.J. \& Pierce, N. E. (2004). The evolution of alternative parasitic life histories in large blue butterflies. Nature 432, 386-390.

Antonov, A., Stokke, B., Moksnes, A., Kleven, O., Honza, M. \& Røskaft, E. (2006). Eggshell strength of an obligate brod parasite: a test of the puncture resistance hypothesis. Behavioral Ecology and Sociobiology 60, 11-18.

Antonov, A., Stokke, B. G., Moksnes, A. \& Røskaft, E. (2008a). Does the cuckoo benefit from laying unusually strong eggs? Animal Behaviour 76, 1893-1900.

Antonov, A., Stokke, B. G., Moksnes, A. \& Røskaft, E. (2008b). Getting rid of the cuckoo Cuculus canorus egg: why do hosts delay rejection? Behavioral Ecology 19, $100-107$

Antonov, A., Stokke, B. G., Moksnes, A. \& Røskaft, E. (2009). Evidence for egg discrimination preceding failed rejection attempts in a small cuckoo host. Biology Letters 5, 169-171.
Aviles, J. M. (2008). Egg colour mimicry in the common cuckoo Cuculus canorus as revaled by modelling host retinal function. Proceedings of the Royal Society B 275, $2345-2352$.

Aviles, J. M., Vikan, J. R., Fossoy, F., Antonov, A., Moksnes, A., Røskaft, E. \& SтоккE, B. G. (2010). Avian colour perception predicts behavioural responses to experimental brood parasitism in chaffinches. Foumal of Evolutionary Biology 23, $293-301$.

Bagneres, A. G., Lorenzi, M. C., Dusticier, G., Turillazzi, S. \& Clement, J. L. (1996). Chemical usurpation of a nest by paper wasp parasites. Science 272, 889-892.

Barbero, F., Bonelli, S., Thomas, J. A., Balletto, E. \& Schönrogge, K. 2009). Acoustical mimicry in a predatory social parasite of ants. Fournal of Experimental Biology 212, 4084-4090.

Barrett, R. D. H., Rogers, S. M. \& Schluter, D. (2008). Natural selection on a major armor gene in threespine stickleback. Science 322, 255-257.

Bauer, S., Böhm, M., Witte, V. \& Foitzik, S. (2010). An ant social parasite in-between two chemical disparate host species. Evolutionary Ecology 24, 317-332.

Begon, M., Harper, J. L. \& Townsend, C. R. (1996). Ecology. Blackwell Science Ltd, Oxford.

Best, A., White, A. \& Boots, M. (2008). Maintenance of host variation in tolerance to pathogens and parasites. Proceedings of the National Academy of Sciences USA 105 20786-20791.

Bogusch, P., Kratochvil, L. \& Straka, J. (2006). Generalist cuckoo bees Hymenoptera: Apodea: Sphecodes) are species specialist at the individual level. Behavioral Ecology and Sociobiology 60, 422-429.

Bourke, A. F. G. \& Franks, N. R. (1995). Social Evolution in Ants. Princeton University Press, Princeton.

Brandt, M. \& Foitzik, S. (2004). Community context and specialization influence coevolution between a slavemaking ant and its hosts. Ecology 85, 2997-3009.

Brandt, M., Foitzik, S., Fischer-Blass, B. \& Heinze, J. (2005a). The coevolutionary dynamics of obligate social parasite systems - between prudence and antagonism. Biological Reviewes 80, 251-267.

Brandt, M., Heinze, J., Schmitt, T. \& Foitzik, S. (2005b). A chemical level in the coevolutionary arms race between an ant social parasite and its hosts. Fournal of Evolutionary Biology 18, 576-586.

Britton, N. F., Planque, R. \& Franks, N. R. (2007). Evolution of defence portfolios in exploiter-victim systems. Bulletin of Mathematical Biology 69, 957-988.

Brooke, M. D. L. \& DAvies, N. B. (1988). Egg mimicry by cuckoos Cuculus canorus in relation to discrimination by hosts. Nature $335,630-632$.

Brooke, M. D. L., Davies, N. B. \& Noble, D. G. (1998). Rapid decline of host defences in reponse to reduced cuckoo parasitism: behavioural flexibility of reed warblers in a changing world. Proceedings of the Royal Society B 265, 1277-1282.

Brooker, M. G. \& Brooker, L. C. (1991). Eggshell strength in cuckoos and cowbirds. Ibis 133, 406-413.

Brooker, M. G. \& Brooker, L. C. (1996). Acceptance by the splendid fairy-wren of parasitism by Horsfiled's bronze-cuckoo: further evidence for evolutionary equilibrium in brood parasitism. Behavioral Ecology 7, 395-407.

Brown, J. L., Morales, V. \& Summers, K. (2009). Tactical reproductive parasitism via larval cannibalism in Peruvian poison frogs. Biology Letters 5, 148-151.

Buschinger, A. (2009). Social parasitism among ants: a review (Hymenoptera: Formicidae). Myrmecological Newes 12, 219-235.

Cassey, P., Honza, M., Grim, T. \& Hauber, M. E. (2008). The modelling of avian visual perception predicts behavioural rejection responses to foreign egg colours. Biology Letters 4, 515-517.

Cervo, R. (2006). Polistes wasps and their social parasites: an overview. Annales Zoologici Fennici 43, 531-549.

Clutton-Brock, T. H. (1991). The Evolution of Parental Care. Princeton University Press, Princeton.

Cotter, S. C. \& Kilner, R. M. (2010). Personal immunity versus social immunity. Behavioral Ecology 21, 663-668.

Davies, N. B. (2000). Cuckoos, cowbirds and other cheats. T. and A. D. Poyser, London.

Davies, N. B., Bourke, A. F. G. \& Brooke, M. D. L. (1989). Guckoos and parasitic ants: interspecific brood parasitism as an evolutionary arms race. Trends in Ecology and Evolution 4, 274-278.

Davies, N. B. \& Brooke, M. D. L. (1988). Cuckoos versus reed warblers: adaptation and counter-adaptations. Animal Behaviour 36, 262-284.

Davies, N. B. \& Brooke, M. D. L. (1989). An experimental study of co-evolution between the cuckoo Cuculus canorus and its hosts. I Host egg discrimination. Fournal of Animal Ecology 58, 207-224.

Davies, N. B., Brooke, M. D. L. \& Kacelnik, A. (1996). Recognition errors and probability of parasitism determine whether reed warblers should accept or reject cuckoo eggs. Proceedings of the Royal Society B 263, 925-931.

Davies, N. B. \& Welbergen, J. A. (2008). Cuckoo-hawk mimicry? An experimental test. Proceedings of the Royal Society B 275, 1817-1822.

D'EtTore, P. \& Errrard, C. (1998). Chemical disguise during colony founding in the dulotic ant Polyergus rufescens Latr. (Hymenoptera, Formicidae). Insect Social Life 2 , $217-224$ 
D’Ettorre, P., Brunner, E., Wenseleers, T. \& Heinze, J. (2004). Knowing your enemies: seasonal dynamics of host-social parasite recognition. Naturevissenschaften $\mathbf{9 1}$, 594-597.

D'Ettorre, P., Mondy, N., Lenoir, A. \& Errard, C. (2002). Blending in with the crowd: social parasites integrate into their host colonies using a flexible chemical signature. Proceedings of the Royal Society B 269, 1911-1918.

Double, M. G., Peakall, R., Beck, N. R. \& Cockburn, A. (2005). Dispersal, philopatry, and infidelity: Dissecting local genetic structure in superb fairy-wrens Malurus cyaneus. Evolution 59, 625-635.

Dronnet, S., Simon, X., Verhaeghie, J.-C., Rasmont, P. \& Errard, C. (2005). Bumblebee inquilinism in Bombus (Fernaldaepsithyrus) sylvestris (Hymenoptera, Apidae): behavioural and chemical analyses of host-parasite interactions. Apidologie 36, 59-70.

Elmes, G. W., Akino, T., Thomas, J. A., Clarke, R. T. \& KnapP, J. J. (2002). Interspecific differences in cuticular hydrocarbon profiles of Myrmica ants are sufficiently consistent to explain host specificity by Maculinea (large blue) butterflies. Oecologia 130, 525-535.

Errard, C., Ruano, F., Richard, F.-J., Lenoir, A., Tinaut, A. \& Hefetz, A. (2006). Coevolution-driven cuticular hydrocarbon variation between the slavemaking ant Rossomyrmex minuchae and its hosts Proformica longiseta (Hymenoptera: Formicidae). Chemoecology 16, 235-240.

Fanelli, D., Henshaw, M., Cervo, R., Turillazzi, S., Queller, D. C. \& Strassmann, J. E. (2005). The social parasite wasp Polistes atrimandibularis does not form host races. Fournal of Evolutionary Biology 18, 1362-1367.

Fineblum, W. \& Rauscher, M. (1995). Tradeoff between resistance and tolerance to herbivore damage in a morning glory. Nature $377,517-520$.

Fisher, R. M. \& SAMPson, B. J. (1992). Morphological specialization of the bumble bee social parasite Psithymus ashtoni (Cresson) (Hympenoptera, Apidae). Canadian Entomologist 124, 69-77.

FoitziK, S., ACHenbach, A. \& BRAndt, M. (2009). Locally adapted social parasite affects density, social structure, and life history of its ant hosts. Ecology 90, 1195-1206.

Foitzik, S., DeHeer, C. J., Hunjan, D. N. \& Herbers, J. M. (2001). Coevolution in host-parasite systems: behavioural strategies of slave-making ants and their hosts. Proceedings of the Royal Society B 268, 1139-1146.

Foitzik, S. \& Herbers, J. (2001). Colony structure of a slavemaking ant. II Frequency of slave raids and impact on the host population. Evolution 55, 316-323.

Foss $\emptyset$ y, F., Antoniv, A., Moksnes, A., Røskaft, E., Vikan, J. R., Møller, A. P., SнукоғF, J. А. \& Sтокке, B. G. (2011). Genetic differentiation among cuckoo host races: males matter. Proceedings of the Royal Society $B$.

Frank, S. A. (1998). Inducible defence and the social evolution of herd immunity. Proceedings of the Royal Society B 265, 1911-1913.

GAVRILETS, S. (1997). Coevolutionary chase in exploiter-victim systems with polygenic characters. Foumal of Theoetical Biology 95, 527-534.

Gibbs, H. L., Sorenson, M. D., Marchetti, K., Brooke, M. D., Davies, N. B. \& NakAmura, H. (2000). Genetic evidence for female host-specific races of the common cuckoo. Nature 407, 183-186.

GLADStone, D. E. (1981). Why are there no slave rebellions. American Naturalist 117, $779-781$.

GRIM, T. (2006). The evolution of nestling discrimination by hosts of parasitic birds: why is rejection so rare? Evolutionary Ecology Research 8, 785-802.

GRIM, T. (2007). Experimental evidence for chick discrimination without recognition in a brood parasite host. Proceedings of the Royal Society B 274, 373-381.

GuiguenG, M. F. \& SeALY, S. G. (2010). Clutch abandonment by parasitized yellow warblers: egg burial or nest desertion? Condor 112, 399-406.

HAUber, M. E. (2003). Interspecific brood parasitism and the evolution of host clutch sizes. Evolutionary Ecology Research 5, 559-570.

Hauber, M. E., Moskat, C. \& Ban, M. (2006). Experimental shift in hosts' acceptance theshold of inaccurate-mimic brood parasite eggs. Biology Letters 2, $177-180$.

Herbers, J. M. \& FoITZik, S. (2002). The ecology of slavemaking ants and their hosts in north temperate forests. Ecology 83, 148-163.

HILL, D. P. \& SEALY, S. G. (1994). Desertion of nests parasitised by cowbird: have claycoloured sparrows evolved an anti-parasite strategy? Animal Behaviour 48, 1063-1070.

Hölldoberer, B. \& Wilson, E. O. (1990). The Ants. Harvard University Press, London, England.

Honza, M., Picman, J., Grim, T., Novak, V., Capek, M. \& Mrlik, V. (2001). How to hatch from an egg of great structural strength. A study of the common cuckoo. fournal of Avian Biology 32, 249-255.

Hoover, J. P. \& Robinson, S. K. (2007). Retaliatory mafia behavior by a parasitic cowbird favors host acceptance of parasitic eggs. Proceedings of the National Academy of Sciences USA 104, 4479-4483.

Hosoi, S. A. \& Rothstein, S. I. (2000). Nest desertion and cowbird parasitism: evidence for evolved responses and evolutionary lag. Animal Behaviour 59, 823-840.

Johnson, B. R., Wigenburg, E. v. \& Tsutsui, N. D. (2011). Nestmate recognition in social insects: overcoming physiological constraints with collective decision making. Behavioral Ecology and Sociobiology, doi: 10.1007/s00265-010-1094-x/

KiLNER, R. (2010). Learn to beat an identify cheat. Nature 463, 165-167.

Kilner, R. M. (2006). The evolution of egg colour and patterning in birds. Biological Revieres 81, 383-406.
Kilner, R. M., Noble, D. G. \& Davies, N. B. (1999). Signals of need in parentoffspring communication and their exploitation by the common cuckoo. Nature 397 , $667-672$.

Kopp, M. \& Gavrilets, S. (2006). Multilocus genetics and the coevolution of quantitaive traits. Evolution 60, 1321-1336.

Lahti, D. (2006). Persistence of egg recognition in the absence of cuckoo brood parasitism: Pattern and mechanism. Evolution 60, 157-168.

Lahti, D. C. (2005). Evolution of bird eggs in the absence of cuckoo parasitism. Proceedings of the National Academy of Sciences USA 102, 18057-18062.

Lahti, D. C., Johnson, N. A., Ajie, B. C., Отto, S. P., Hendry, A. P., BlumStein, D. T., Coss, R. G., Donohue, K. \& Foster, S. A. (2010). Relaxed selection in the wild. Trends in Ecology and Evolution 24, 487-496.

Langmore, N. E., Cockburn, A., Russell, A. F. \& Kilner, R. M. (2009a). Flexible cuckoo chick rejection rules in the superb fairy-wren. Behavioral Ecology 20, 978-984.

LANGMORE, N. E., Hunt, S. \& KilneR, R. M. (2003). Escalation of a co-evolutionary arms race through host rejection of brood parasitic young. Nature 422, 157-160.

Langmore, N. E. \& Kilner, R. M. (2007). Breeding site and host selection by Horsfield's bronze-cuckoos, Chalcites basalis. Animal Behaviour 74, 995-1004.

Langmore, N. E. \& Kilner, R. M. (2009). Why do Horsfield's bronze-cuckoo Chalcites basalis eggs mimic those of their hosts? Behavioral Ecology and Sociobiology 63, 1127-1131.

Langmore, N. E. \& Kilner, R. M. (2010). The coevolutionary arms race between Horsfield's bronze-cuckoos and superb fairy-wrens. Еmu 110, 32-38,

Langmore, N. E., Kilner, R. M., Butchart, S. H. M., Maurer, G., Davies, N. B., Cockburn, A., Macgregor, N. A., Peters, A., Magrath, M. J. L. \& DowLING, D. K. (2005). The evolution of egg rejection by cuckoo hosts in Australia and Europe. Behavioral Ecology 16, 686-692.

Langmore, N. E., Maurer, G., Adcock, A. J. \& Kilner, R. M. (2008). Socially acquired host-specific mimicry and the evolution of host races in Horsfield's BronzeCuckoo Chalcites basalis. Evolution 62, 1689-1699.

Langmore, N. E., Stevens, M., Maurer, G., Heinsohn, R., Hall, M. L., Peters, A. \& Kilner, R. M. (2011). Visual mimicry of host nestlings by cuckoos. Proceedings of the Royal Society B, doi: 10.1098/rspb.2010.2391.

Langmore, N. E., Stevens, M., Maurer, G. \& Kilner, R. M. (2009b). Are dark cuckoo eggs cryptic in host nests? Animal Behaviour 78, 461-468.

Lawes, M. J. \& Kirkman, S. (1996). Egg recognition and interspecific brood parasitism rates in red bishops. Animal Behaviour 52, 553-563.

Lenoir, A., D'Ettorre, P., Errard, C. \& Hefetz, A. (2001). Chemical ecology and social parasitism in ants. Annual Review of Entomology 46, 573-599.

Lотем, A. (1993). Learning to recognize nestlings is maladaptive for cuckoo Cuculus canorus hosts. Nature $362,743-745$.

Lotem, A., Nakamura, H. \& Zahavi, A. (1992). Rejection of cuckoo eggs in relation to host age: a possible evolutionary equilibrium. Behavioral Ecology 3, 128-132.

Lotem, A., Nakamura, H. \& Zahavi, A. (1995). Constraints on egg discrimination and cuckoo host coevolution. Animal Behaviour 49, 1185-1209.

Lyon, B. E. \& EAdie, J. M. (2004). An obligate brood parasite trapped in the intraspecific arms race of its hosts. Nature 432, 390-393.

Marchant, S. (1972). Evolution of the genus Chrysococcyx. Ibis 114, 219-233.

MarchetTi, K. (1992). Costs to host defense and the persistence of parasitic cuckoos. Proceedings of the Royal Society B 248, 41-45.

Marchetti, K. (2000). Egg rejection in a passerine bird: size does matter. Animal Behaviour 59, 877-883.

Martin, S. J., Carruthers, J. M., Williams, J. H. \& Drijfhout, F. P. (2010a). Host specific social parasites (Psithyrus) indicate chemical recognition system in bumblebees. Foumal of Chemical Ecology 36, 855-863.

Martin, S. J. \& Drijfhout, F. P. (2009). A review of ant cuticular hydrocarbons. Foumal of Chemical Ecology 35, 1151-1161.

Martin, S. J., Helanterä, H. \& Drijfhout, F. P. (2008a). Colony-specific hydrocarbons identify nest mates in two species of Formica ant. Fournal of Chemical Ecology 34, 1072-1080.

Martin, S. J., Helanterä, H. \& Drijfhout, F. P. (2010b). Is parasite pressure a driver of chemical cue diversity in ants? Proceedings of the Royal Society B, doi: 10.1098/rspb.2010.1047.

Martin, S. J., Jenner, E. A. \& Drijfhout, F. P. (2007). Chemical deterrent enables a socially parasitic ant to invade multiple hosts. Proceedings of the Royal Society $B$ 274, $2717-2721$.

Martin, S. J., Takahashi, J., Ono, M. \& Drijfhout, F. P. (2008b). Is the social parasite Vespa dybowskii using chemical transparency to get her eggs accepted? Fournal of Insect Physiology 54, 700-707.

Mock, D. W. \& Parker, G. A. (1997). The Evolution of Sibling Rivaly. Oxford University Press, Oxford.

Moksnes, A., RøSKaft, E. \& BRAa, A. T. (1995). Rejection behaviour by Common Cuckoo hosts towards artificial brood parasite eggs. Auk 108, 348-354.

Mori, A., D’Ettorre, P. \& Le Moli, F. (1995). Host nest usurpation and colony foundation in the European amazon ant, Polyergus rufescens Latr. (Hymenoptera: Formicidae). Insectes Sociaux 42, 279-286.

Mori, A., Grasso, D. A., Visichio, R. \& Le Moli, F. (2000). Colony founding in Polvergus rufessens: the role of the Dufour's gland. Insectes Sociaux 47, 7-10. 
Moskat, C. \& Honza, M. (2002). European cuckoo Cuculus canorus parasitism and host's rejection behaviour in a heavily parasitized great reed warbler Acrocephalus arundinaceus population. Ibis 144, 614-622.

Nuismer, S. L., Doebeli, M. \& Browning, D. (2005). The coevolutionary dynamics of antagonistic interactions mediated by quantitative traits with evolving variances. Evolution 59, 2073-2082.

Nuismer, S. L., Ridenhour, B. J. \& Oswald, B. P. (2007). Antagonistic coevolution mediated by phenotypic differences between quantitative traits. Evolution 61, $1823-1834$.

Ortolani, I. \& Cervo, R. (2010). Intra-specific body size variation in Polistes paper wasps as a response to social parasite pressure. Ecological Entomology 35, 352-359.

Pagel, M., Møller, A. P. \& Pomiankowski, A. (1998). Reduced parasitism by retaliatory cuckoos selects for hosts that rear cuckoo nestlings. Behavioral Ecology $\mathbf{9}$, $566-572$.

Picman, J. (1989). Mechanism of increased puncture resistance of eggs of brownheaded cowbirds. Auk 106, 577-583.

Picman, J. \& Pribil, S. (1997). Is greater eggshell density an alternative mechanism by which parasitic cuckoos increase the strength of their eggs? Journal fur Ormithologie 138, 531-541.

Pierce, N. E., Braby, M. F., Heath, A., Lohman, D. J., Mathew, J., Rand, D. B. \& Travassos, M. A. (2002). The ecology and evolution of ant association in the Lycaenidae (Lepidoptera). Annual Review of Entomology 47, 733-771.

Planque, R., Britton, N. F., Franks, N. R. \& Peletier, M. A. (2002). The adaptiveness of defence strategies against cuckoo parasitism. Bulletin of Mathematical Biology 64, 1045-1068.

RÅboRG, L., Sim, D. \& READ, A. (2007). Disentangling genetic variance for resistance and tolerance to infectious diseases in animals. Science 318, 812-814.

Robert, M. \& Sorci, G. (1999). Rapid increase of host defence against brood parasites in a recently parastized area: the case of village weavers in Hispaniola. Proceedings of the Royal Society B 266, 941-946.

Robert, M., Sorci, G., Møller, A. P., Hochberg, M. E., Pomiankowski, A. \& PAGEL, M. (1999). Retaliatory cuckoos and the evolution of host resistance to brood parasites. Animal Behaviour 58, 817-824.

Rodriguez-Girones, M. A. \& Lotem, A. (1999). How to detect a cuckoo egg: a signal-detection theory model for recognition and learning. American Naturalist 153, 633-648.

Rohwer, S., Spaw, C. D. \& Røskaft, E. (1989). Costs to northern orioles of punctureejecting parasitic cowbird eggs from their nests. Auk 106, 734-738.

Rothstein, S. I., Patten, M. A. \& Fleischer, R. C. (2002). Phylogeny, specialization, and brood parasite-host coevolution: some possible pitfalls of parsimony. Behavioral Ecology 13, 1-10.

Rothstein, S. I. \& Robinson, S. K. (1998). Parasitic Birds and their Hosts: Studies in Coevolution. OUP, Oxford.

Ruxton, G. D., Sherratt, T. N. \& Speed, M. P. (2004). Avoiding Attack: The evolutionary ecology of crypsis, warning signals and mimicry. Blackwell Science Ltd, Oxford.

Sato, N. J., Tokue, K., Noske, R. A., Mikami, O. K. \& Ueda, K. (2010). Evicting cuckoo nestlings from the nest: a new anti-parasitism behaviour. Biology Letters $\mathbf{6}$, $67-69$.

SAto, T. (1986). A brood parasitic catfish of mouthbrooding cichlid fishes in Lake Tanganyika. Nature $\mathbf{3 2 3}, 58-59$

Schönrogge, K., Gardner, M. G., Elmes, G. W., Napper, E. K. V., Simcox, D. J., Wardlaw, J. G., Breen, J., Barr, B., Knapp, J. J., Pickett, J. A. \& Thomas, J. A. (2006). Host propagation permits extreme local adaptation in a social parasite of ants. Ecology Letters 9, 1032-1040.

Servedio, M. R. \& Hauber, M. E. (2006). To eject or to abandon? Life history traits of hosts and parasites interact to influence the fitness payoffs of alternative anti-parasite strategies. Fournal of Evolutionary Biology 19, 1585-1594.

Shizuka, D. \& Lyon, B. E. (2010). Coots use hatch order to learn to recognize and reject conspecific brood parasitic chicks. Nature 463, 223-226.
Soler, J. J., Martinez, J. G., Soler, M. \& Møller, A. P. (2001). Life history of magpie populations sympatric or allopatric with the brood parasitic great spotted cuckoo. Ecology 82, 1621-1631.

Soler, J. J., Soler, M., Perez-Contreras, T., Aragon, S. \& Møller, A. P. (1999a). Antagonistic antiparasite defenses: nest defense and egg rejection in the magpie host of the great spotted cuckoo. Behavioral Ecology 10, 707-713.

Soler, J. J., Sorci, G., Soler, M. \& Møller, A. P. (1999b). Change in host rejection behavior mediated by the predatory behavior of its brood parasite. Behavioral Ecolog) 10, $275-280$.

Soler, M., Soler, J.J., Martinez, J. G. \& Møller, A. P. (1995). Magpie host manipulation by great spotted cuckoos - evidence for an avian mafia. Evolution 49 $770-775$.

Sorenson, M. D. \& Payne, R. B. (2005). A molecular genetic analysis of the cuckoo phylogeny. In The Cuckoos (ed. R. B. PAYNE), pp. 68-94. OUP, Oxford.

Spaw, C. D. \& Rohwer, S. (1987). A comparative study of eggshell thickness in cowbirds and other passerines. Condor 89, 307-318.

Spottiswoode, C. N. (2010). The evolution of host-specific variation in cuckoo eggshell strength. Fournal of Evolutionary Biology 23, 1792-1799.

Spottiswoode, C. N. \& Stevens, M. (2010). Visual modelling shows that avian host parents use multiple visual cues in rejecting parasitic eggs. Proceedings of the National Academy of Sciences USA 107, 8672-8676.

Stoddard, M. C. \& Stevens, M. (2010). Pattern mimicry of host eggs by the common cuckoo, as seen through a bird's eye. Proceedings of the Royal Society B 277, $1387-1393$

Stokke, B. G., Honza, M., Moksnes, A., Røskaft, E. \& Rudolfsen, G. (2002). Costs associated with recognition and rejection of parasitic eggs in two European passerines. Behaviour 139, 629-644.

Svennungsen, T. O. \& HøLen, Ø. H. (2010). Avian brood parasitism: information use and variation in egg-rejection behavior. Evolution 64, 1459-1469.

Svensson, E. I. \& RÅBoRG, L. (2010). Resistance and tolerance in animal enemyvictim coevolution. Trends in Ecology and Evolution 25, 267-274.

TAKasu, F. (2003). Co-evolutionary dynamics of egg appearance in avian brood parasitism. Evolutionary Ecology Research 5, 345-362.

Thompson, J. N. (2005). The Geographic Mosaic of Coevolution. University of Chicago Press, Chicago.

Tokue, K. \& UedA, K. (2010). Mangrove gerygones Gerygone laevigaster eject Little Bronze-cuckoo Chalcites minutillus hatchlings from parasitized nests. Ibis 152, $835-839$.

Trivers, R. L. (1971). Evolution of reciprocal altruism. Quarterly Review of Biology 46, $35-57$.

Tsuneoka, Y. \& Akino, T. (2009). Repellent effect on host Formica workers of queen Dufour's gland secretion of the obligatory social parasite ant, Polyergus samurai (Hymenoptera:Formicidae). Applied Entomology and Zoology 44, 133-141.

Vikan, J. R., Stokke, B. G., Rutila, J., Huhta, E., Mosknes, A. \& Røskaft, E. (2010). Evolution of defences against cuckoo (Cuculus canorus) parasitism in bramblings (Fringilla montifringilla): a comparison of four populations in Fennoscandia. Evolutionary Ecology 24, 1141-1157.

Welbergen, J. A. \& Davies, N. B. (2009). Strategic variation in mobbing as a front line defence against cuckoo parasitism. Current Biology 19, 235-240.

West-Eberhard, M. J. (2003). Developmental plasticity and evolution. Oxford University Press, Oxford.

Yang, G., Liang, W., Cai, Y., Shi, S., Takasu, F., Møller, A. P., Antonov, A., Foss $\emptyset$ Y, F., Moksnes, A., Røskaft, E. \& Stokke, B. (2010). Coevolution in action: disruptive selection on egg colour in an avian brood parasite and its host. Public Library of Science ONE 5, e10816.

Zamora-Muñoz, G., Ruano, F., Errard, C., Lenoir, A., Hefetz, A. \& Tinaut, A. (2003). Co-evolution in the slave-parasite system Proformica longisetaRossomyrmex minuchae (Hymenoptera: Formicidae). Sociobiology 42, 299-317.

(Received 1 November 2010; revised 14 December 2010; accepted 17 December 2010; published online 12 January 2011) 